Susan Gardner. The Impact of Electronic Journals on Library Staff at ARL-Member Institutions. A Master's paper for the M.S. in L.S. degree. July, 2000. 63 pages. Advisor : Evelyn Daniel.

This study examines how Association of Research Library (ARL)-member institutions are meeting the challenges of electronic journals in terms of staffing. The differences between the linear print journal workflow and the more time-consuming, nonlinear electronic journal workflow are discussed. ARL members are dealing with the increased demand on staff and workload caused by e-journals in different ways. Most of the respondents did not have a job upgrade, but did receive informal training. New positions have been created to deal with e-journals in acquisitions, serials, and cataloging departments. Other specialty positions have been created that require eclectic duties normally relegated to individual departments. There is at least some standardization now in the libraries' procedures for negotiating license agreements. However, libraries continue struggling to integrate e-journals seamlessly into their workflow without upsetting the pre-existing departmental structure. The overriding effect of e-journals on staff appears to be increased synergy and broader specialization.

Headings:

Electronic journals

Electronic journals - Acquisitions

Research libraries - Serial publications

Research libraries - Staff 
Periodicals - Colleges and universities

\title{
THE IMPACT OF ELECTRONIC JOURNALS ON LIBRARY STAFF AT ARL-MEMBER INSTITUTIONS
}

\author{
by \\ Susan Gardner
}

\begin{abstract}
A Master's paper submitted to the faculty of the School of Information and Library Science of the University of North Carolina at Chapel Hill

in partial fulfillment of the requirements for the degree of Master of Science in Library Science.
\end{abstract}

\section{Chapel Hill, North Carolina}

July, 2000

Approved by:

Advisor 


\section{Table of Contents}

Table of Contents

Table of Figures ii

Table of Tables iv

Introduction 1

Literature Review 3

Methodology 22

Results and Analysis 25

Conclusion $\quad 46$

Appendix A - Email To Survey $\quad 50$

Participants

Appendix B - Survey 52

Appendix C - Distribution List $\quad 58$

Bibliography 62 


\section{Table of Figures}

Figure 1 - Depts. Involved With E-Journals $\quad 25$

Figure 2 - Number of Staff Who Work With E-Journals 27 Compared to Print Journals

Figure 3 - Amount of Staff Time Spent on E-Journals Compared to Print Journals

Figure 4 - Selectors of E-Journals 28

Figure 5 - Who Reviews E-Journal Selections? 29

Figure 6 - Reviewers of E-Journal Selections in Libraries 30 With Smaller Amount of Staff

Figure 7 - Reviewers of E-Journal Selections in Libraries $\quad 30$ With Medium-Sized Amount of Staff

Figure 8 -- Special Selection Review Committee 31

Figure 9 - Number of Professional Staff Involved With 31 Ordering Process

Figure 10 - Do You Have Any Legal Consultants Who Help 32 With Licenses?

Figure 11 - Who Negotiates License Agreements? 33

Figure 12 - Who Negotiates Licenses in Libraries With Small 34 Amount of Staff?

Figure 13 - Who Negotiates Licenses in Libraries With 34 Medium-Sized Amount of Staff?

Figure 14 - Is There A Standardized Procedure For 35 Negotiating License Agreements?

Figure 15 - License Negotiation Among Libraries With 35 Small Staff

Figure 16 - License Negotiation Among Libraries With 35 Medium-Sized Staff 
Figure 17 - Who Archives Back Issues of E-Journals? 37

Figure 18 - Bibliographic Control Over E-Journals 38

Figure 19 - Dept. Responsible For Bibliographic Control 38

Figure 20 - How Do You Update E-Journals? 39

Figure 21 - Number of Upgraded Job Descriptions or $\quad 40$ Classification Levels For Serials Librarians

Figure 22 - Supplemental Help With E-Journals 41

Figure 23 - New Positions Created As A Result 42 Of E-Journals 


\section{Table of Tables}

Table 1 - New Positions Created For E-Journals In Libraries 43 With A Small Staff Over The Past 2 Years

Table 2 - New Positions Created For E-Journals In Libraries 43 With A Medium-Sized Staff Over The Past 2 Years

Table 3 - New Positions Created For E-Journals In Libraries 43 With A Large Staff Over The Past Year

Table 4 - Departmental Activity 


\section{Introduction}

Libraries are overwhelmed by the onslaught of technological progress in recent years. Aside from the fact that cataloging, ordering, and Interlibrary Loans have all been transformed by shared networks such as OCLC and RLIN, nearly all library catalogs are now online. Furthermore, reference material previously available only in print format is being made available through electronic means. This digital revolution is changing the role of both the library and the librarian. In an article that describes the impact of technology on the acquisitions department of the University Libraries of Notre Dame,

Gleason and Zeugner assert that technology has been a huge "catalyst for change" (306). They explain that technology blurred the lines between acquisition and cataloging functions in their library back in 1993. In response to this, the library streamlined certain operations and reorganized the departments into "team-like sections" (306). The library also formed a committee made up of acquisitions and cataloging people; the end result was collaboration rather than the cooperation that had existed previously. The authors prescribe "radical change as the only course for libraries who wish to have a future" (309), and they insist that a "transformation, not a refining" (309) is necessary. It turns out that Notre Dame's proactive response to technology is now being copied by libraries everywhere. 
(commonly referred to as e-journals) are causing libraries a great deal of stress. The major difference between the e-journal and its print journal predecessor is the fact that an e-journal is licensed rather than purchased. This means the process of acquiring and maintaining them differs at almost every stage of the procedure, and the preexisting model used for the print serials medium is no longer sufficient. The difficulty in acquiring and maintaining electronic journals has been referred to as the "serials crisis" in recent articles (Duranceau "Beyond..." 84). How, then, are libraries coping with the influx of electronic serials? This paper surveys how one group of libraries are meeting the challenges of electronic journals in terms of staffing. It will examine how staffing has been affected by electronic journals and what implications this has for the future organizational structure of the library. Are new positions being created to assist serials librarians who are no longer able to handle the new demands of the electronic journal by themselves, or have the new responsibilities shifted towards other departments? The answer will affect the roles and jobs of many librarians. If libraries, in response to technology, are continuing the already-existing trend of reorganizing their departmental structures into team-like units that are less clearly defined, then the distinction between public service positions, systems, collection development, and acquisitions is becoming fuzzy. Are library departments becoming even less specialized in order to accommodate electronic journals? Are standardized measures being used to deal with e-journals among the leading institutional libraries? Have e-journals been integrated seamlessly into a new model of acquisitions workflow? If so, this can serve as a helpful model for other libraries who have not yet successfully made the transition. 


\section{Literature Review}

\section{Libraries and Electronic Journals}

The Ellis article entitled "Acquiring Electronic Journals" is a good place to learn about the basic features of e-journals. Unlike the fixed print journal format, electronic journals are available in several formats. Although some e-journals are freely available over the Internet, most scholarly journals that a library wishes to acquire are available for a fee. Of these fee-based e-journals, some are networked while others are non-networked. Networked journals are those distributed over the World Wide Web (WWW) (Ellis 7-8). A small percentage of networked e-journals are comprised of ASCII text and delivered via email. A more popular method is the Portable Data Format (PDF); this produces an exact replica of a printed page but cannot handle links and requires a helper application (Buckley 7). The trend is shifting more towards formatted text such as HTML or the increasingly-popular SGML, both of which are able to include graphics, images, and links (Ellis 6-7; Buckley 7). Non-networked e-journals are those that are delivered by mechanisms such as CD-ROMs and diskettes. However, these non-networked e-journals can be "networked" locally by a library for patrons so that, at the user level, they are just like networked journals (Ellis 7).

Networked e-journals are usually accessible to users by the regulation of the physical four-part address of a computer attached to the Internet, known as the Internet Protocol (IP) domain; this allows all users within the authorized IP range to have access. In order for simultaneous access to occur within the same domain, passwords are developed that 
are masked by a script so that users experience no break in their log-on process (Dygert 10). If a user is accessing an e-journal from outside of the IP domain, he/she must use a proxy server or other type of transitional technology to authenticate the address. Usually a password and log-in are required for this method of access (Dygert 10-11). Some institutions serve as Internet Service Providers (ISP) for their authorized users; this allows a patron to dial into the campus network and appear to have the institutional domain address necessary for access (Chadwell/Brownmiller 30).

The purchase options for e-journal access are varied. Some can be purchased by direct subscription from a publisher, others through a subscription vendor, others can be accessed through software, and still others through an aggregator service that provides multiple collections of e-journals together. In all cases, but particularly in the latter, a subscription does not always include both access and content. In some cases, they are separate: the library must have separate subscriptions for the actual titles they want through the service (Ellis 11). To further complicate matters, the aggregator service is sometimes only available through a vendor rather than directly (Ellis 7). The content also varies: some services offer full-text access, others only abstracts, and still others only a citation. Currently, the leading publisher products that offer at least some full-text access are Academic Press' IDEAL, Elsevier Science’s DIRECT, Kluwer's KLUWER ONLINE, Springer's LINK, and Wiley's INTERSCIENCE (Luther 26). The current principal subscription agents are EBSCO ONLINE, INFORMATION QUEST, and SWETSNET (Luther 26). Software that offers full-text access includes OVID's "Full Text Online," OCLC's “Electronic Collections Online” (ECO), and Silverplatter's "Silverlinker" (Luther 26). Finally, some of the leading aggregators are EBSCO 
Publishing's EBSCOhost, Gale Group's InfoTrac One File, and Bell \& Howell's Proquest (Luther 26). There are also numerous secondary publishers such as ISI's Web of Science and publisher-societies such as IEEE that offer e-journal access. The newest trends are publishing services like Highwire and Catchword who "provide the technology and support to offer electronic journals" (Luther 24).

Electronic journals vary as to whether or not they have a print counterpart. Eventually, people predict that the print journal medium will completely disappear and be replaced with the electronic medium (Bjoernshause 7). However, we are still far away from the realization of this prophecy. Currently, many journals are being offered in both print and electronic versions. This changes the pricing structure of the journal, because there is no longer necessarily one set price for $\mathrm{x}$ number of issues. Sometimes electronic access to a journal is offered free along with a print subscription. Sometimes the price for adding electronic access to already-existing print subscriptions increases by " $10-20$ percent" (Chadwell/Brownmiller 24). If a library only wants the electronic version of a journal, it is either less than, or the same as, a print subscription (Chadwell/Brownmiller 25). Libraries frequently form consortia to purchase electronic journals together as a group, which leads to discounted prices but complicates pricing models even more (Chadwell/Brownmiller 25). Publishers, similarly, are grouping their products by offering their journals in bundled sets. This means a library has less choice about individual titles and often must settle for titles outside the scope of their collection in order to get other titles they need (Chadwell/Brownmiller 25). 


\section{Changes in Workflow: E-journals Versus Print journals}

Because electronic journals are such a different medium than their print journal predecessors, they cannot be handled in the same way. As Ellen Duranceau declares in her article "Beyond Print: Revisioning Serials Acquisitions for the Digital Age," "webbased serials break the mold...there is simply no way to use a print-based acquisitions model for Web-based serials" (86). Slight-Gibney concurs and explains that "the linear model for the acquisition of print titles (collection development-acquisitions-vendorpublisher-acquisitions-cataloging-shelf-end user) is unsuited to the digital environment" (1). Duranceau compares the workflow used in print serials acquisitions to that used for electronic serials acquisitions at the MIT libraries. The print workflow is a very linear process involving six simple steps performed by a total of six people working independently. Basically, a subject specialist chooses a title, the order is initialed by the Head of Collections Management and placed, then it is entered into the MIT Libraries database, received, cataloged, and shelved (86-87). On the other hand, the workflow for networked serial acquisitions is nonlinear and involves, for the MIT Libraries, a total of fifteen people. Because many web titles are interdisciplinary, one subject specialist can no longer select items at MIT. Instead, a committee known as the Networked Electronic Resources Discussion Group (NERD) that is made up of nine managers and coordinators from a variety of different departments reviews titles. Next, the acquisitions department sets up a trial for the product, which takes up to two months and involves at least nine other people. One person then requests licensing and pricing information, pricing is negotiated, NERD meets again, and the order finally is initialled by the Head of 
Collection Management. After this, the license is negotiated by three people over several weeks, then prepared and signed; meanwhile, the systems department is notified of access methods, IP addresses are sorted out, and links are worked out. Finally, the order gets placed, access is announced and tested, and the title gets cataloged (or not, depending on the decision) (88-92). Obviously, the two processes for print and electronic journals are almost unrecognizably different. Duranceau characterizes the networked serial acquisitions workflow as different from the print-based workflow because it is teambased, requires high-level library staff, requires communication and coordination, is cyclical, and is varied rather than predictable (87). The step-by-step processes and the issues libraries face in trying to carry them out are described in the following section.

\section{Selection}

In the case of the MIT Libraries, a team made up of librarians from various departments selects electronic resources rather than the traditionally solo subject specialist. That this is generally true elsewhere can be inferred from Slight-Gibney's statement "to the question of who or what unit in the library needs to be involved in the decision-making, the answer seems to be "Everybody!" (1). Duranceau's article was published in 1998, but subsequent literature suggests that the team approach continues. In a recent survey posted on Colldev-L and AcqNet-L, 84\% of the respondents said both collection development librarians and others select electronic resources. The most frequent "others" cited were reference librarians (72\%), electronic resources librarians (42\%), and systems librarians (16\%) (Withers 80 ). Furthermore, 61\% of the respondents said that selection decisions are "always" reviewed by someone, usually a committee 
(45\%) or a Department Head or Director. The selection decision committees are usually made up of members from systems (17\%), electronic resources (10\%), and acquisitions (2\%). In a case study at Ohio University, an "electronic resources bibliographer" from the reference department informed subject bibliographers of electronic journals. This eventually turned into an informal group made up of the bibliographer, the collection development coordinator, and the webmaster (Hudson/Windsor 15-16).

\section{Ordering and the License Agreement}

“Ordering” a journal no longer means simply agreeing to pay a publisher or vendor a set price for a set number of physical products. As Claire Dygert asserts in "New Challenges Behind the Scenes: the Changing Role of the Serials Librarian in the Age of E-Publishing," "because of several unique properties of digital information, agreements that govern the acquisition and maintenance of traditional paper collections are inadequate in the digital information context" (10).

What makes e-journals so different? The main difference is that libraries access the information rather than own it. Because no tangible product will end up with the library, all of the legalities must be explicitly stated in the license. First of all, who the user population is must be determined exactly. Is it limited to students and faculty? Does it include all patrons who walk in the library, regardless of their affiliation status? What about visiting scholars? This needs to be spelled out so that access can be granted to all users. The library must decide the locations these users will need access from, and they need to make sure they set up IP addresses or scripts with passwords that will allow users admittance (Duranceau "Beyond..." 97). Another item that must be negotiated in 
license agreements is what exactly constitutes "authorized use" of the information. As no standardized copyright law for digital products currently exists, the degree to which users can quote from, copy, download, share, or print the information must be clarified. How can libraries enforce this, since many users will be accessing the information from home? (Duranceau 97-98). Finally, how long will the "access" to the information last? With print journals, once the library receives a journal, they own it forever. This is not necessarily the case with electronic journals. In the event of a subscription cancellation or a publisher's decision to abandon certain archives from their web sites, will libraries still have access to the information they paid for? This needs to be specified in the license agreement.

Given the questions that plague both licenser and licensee before an agreement is signed, is there a standardized process the library can use for every license agreement to lighten the burden? The literature appears to say no. Crump points out that "licensing agreements must be negotiable in every instance" of acquiring an electronic product, even if it is only a free electronic version of a paper journal that the library already receives (58). The answer to the questions of who the user population is for a given electronic resource, where these users will need access, what the publisher or vendor considers "authorized use" of the product, and how they expect the library to carry the agreement out will differ in every case. Thus, as Slight-Gibney observes, "it seems as if every electronic product is licensed, acquired, and made available in a unique way" (1). Chris Easton, in her article "E-Journals and the Middleperson," even claims "there is no such thing as standard licenses" (103). At the latest North American Serials Interest Group (NASIG) conference, Blosser, a librarian at Northwestern University, discussed 
the need for multiple products to be treated as add-ons "rather than each product having its own license agreement" (Loghrya et al 132). Is there hope for more standardization in licensing? Are libraries already moving towards this goal? According to Burright in her article entitled "Licensing," licensing can become more standardized if libraries develop common templates, common principles, common "legal jargon" vocabulary, blanket licenses, and possibly third party brokering (Buckley et al 11).

Who is negotiating license agreements in libraries at the present time? The MIT Libraries have a license review team to negotiate their contracts. At the most recent Annual North American Serials Interest Group Conference (NASIG), it was disclosed that only slightly more librarians than administrators negotiate licenses (17 versus 14), while "some consortia were involved in negotiations" (Loghyra et al 137). At the 1997 Annual ALA meeting in San Francisco, survey results reported that there was "no clear pattern of where the responsibility for negotiating and signing the license agreements for e-journals resides" (Johnson 62). The most frequently-cited staff members assigned to this task were the collection development director, the acquisitions librarian, subject specialists, and committees (Johnson 62). In a recent informal survey of AcqNet-L and Colldev-L list serve members published by Withers, a wide variety of departmental staff members appear to be involved in negotiation of licenses for electronic products. The most frequently-cited departments were acquisitions (36\%) and the library director (29\%), while collection development (21\%), the assistant director (17\%), and systems (15\%) all received votes as well. Furthermore, electronic resources coordinators (9\%), university purchasing or administration (7\%), and serials, reference, cataloging, and 
copyright librarian all were mentioned! Smaller libraries seem to rely more on acquisitions librarians and directors (Whithers 82).

\section{Maintenance: Cataloging, Archiving, and Updating}

\section{Cataloging}

Cataloging electronic journals is not as simple and straightforward as cataloging print journals. As Duranceau states in her article "Beyond Print...," there is "no longer an assumed path to cataloging after acquisition of a remotely accessed title, as there has been for all but a tiny subset of print material" (103). In the case of the print journal, its arrival in the post would trigger its cataloging and check-in in the library's database. With the electronic journal, there never is a discernible "arrival." Rather, after the license is signed, the appropriate technological set-up is performed, and the library suddenly has access. Furthermore, not all electronic resources are cataloged, especially if it is something only considered a temporary addition to the library, as in the case of the ubiquitous "free trial offer." The whole point of cataloging a journal is to have bibliographic control over the item so that users are made aware of its existence and location. Print journals were added to the library's Online Public Access Catalog (OPAC) by title with the call number information available so that users could locate the item. Yet, there is no physical "location" for an electronic journal, so how do libraries handle this?

According to the literature, some libraries are implementing electronic journal holdings in their OPAC's by providing links to the URL, where appropriate, or the CDROM number where applicable. Obviously, in order to do this, the OPAC must be able to support links. Other libraries appear to be creating separate web pages for their 
electronic journals. According to a recent survey, $62 \%$ of the libraries responding catalog their electronic resources in the OPAC, while 93\% make their resources available via a web page (Withers 82 ). This suggests at least a 55\% overlap- the majority of libraries are doing both. The trouble with mounting separate web pages for e-journals is that users might not always notice them, whereas they automatically check the OPAC. Most libraries attempt to increase user awareness of electronic journals by providing demonstrations and instructional sessions about e-journals (Dygert 13).

How do libraries determine the best way to catalog their electronic journals? The literature suggests that some institutions are once again taking the "team" approach . At Ohio University an "Electronic Journals Task Force" was formed to deal with cataloging electronic resources. The Task Force consists of two catalogers, one reference librarian, and the coordinator for collection development. They decide on issues such as when to refrain from cataloging an e-journal, what the call number ought to be for electronic resources, what the location field ought to say, and whether or not it is effective to maintain a separate electronic journals web page (Withers 16).

\section{Archiving}

Back issues of electronic journals are troublesome to libraries. Most electronic journal services only go back a few years. This means that in order to have the entire collection of a journal libraries must keep the older print versions. Because libraries are getting access rather than ownership, will they even have older issues of an electronic subscription they've paid for if they cancel the subscription? Who is taking responsibility for archiving electronic journals? Traditionally, the library served as a depository for all scholarly serials. Unfortunately, in this country there is no national 
library to take on the responsibility (Duranceau “Archiving...” 112). Currently, "responsibility for archiving seems to be falling to vendors and aggregators" because it is too "costly, time-consuming, and redundant" for libraries to take on this role (Duranceau 102). According to a 1998 survey by Barbara Hall, only $25 \%$ of libraries are archiving ejournals locally (Duranceau “Archiving..." 103). Some publishers offer archival disks after subscription lapses on CD-ROM, thus allowing perpetual rights for the library as long as they have the equipment to support the disk. However, for the most part, the details of archiving have not been worked out yet. It is not easy to duplicate the webbased full text product with all the searching features intact in an archive (Dureanceau 113-114). Furthermore, software, hardware, and the Internet are changing and being enhanced constantly; how does a library anticipate all of the changes and not get caught having outdated equipment?

\section{Updating Holdings}

Updating the bibliographic records and descriptions of electronic journals is much more labor-intensive than it was for print journal holdings. As Duranceau explains, "in the print world, we do not have to continually verify that something we received several years prior is still available..." ("Beyond..." 95). Once the journal arrived in the library and was processed and shelved, it was a permanent physical presence. With electronic journals, there are many things that could change the library's access. Duranceau points out that with electronic resources "we have to monitor the web sites to be sure that they are live and being added to on schedule... also that the entire run of holdings we expect access to is still present" (95). 
When a web site link is not working, the library must determine if it is a problem with the host or with the library's technical equipment. Furthermore, is it only a temporary problem, or a permanent one? Moothart notes that, even if a link is working properly, it is difficult to keep an accurate description posted of journal content because it is constantly changing (137). Dygert concurs, adding that e-journals "blur [the] distinctions" between separate volumes and issues (11). Many electronic journals have shed the distinction completely, opting instead for "continuous publishing" of daily updates, thus expanding constantly. In addition, many publishers are retrospectively digitizing older issues so that the content of their journals change constantly (Dygert 12).

Since so many journals are available now through bundled aggregator services that also change their coverage constantly, how do libraries keep up with which databases provide access to which journals (Moothart 137)? Some journals even have multiple access points; different databases cover different years (often the older issues of the journal are only available in print format), or there is some overlap among databases (Moothart 137). This further adds to the maintenance responsibilities, and it explains why some libraries do not even attempt to exercise bibliographic control over their collections of electronic journals.

Some libraries use link maintenance software to look for broken links and problems in accessing URL's. This cuts down on library labor considerably, but still requires someone to analyze the results and to make the necessary changes (Duranceau "Beyond..." 95). Other libraries rely more on user feedback to determine if there are problems accessing electronic resources, believing this is faster, more efficient, and more cost-effective (Duranceau "Beyond..." 96). If libraries depend on staff members to 
maintain accuracy in the records and actual access of electronic resources, what position is responsible for this? The literature does not discuss this in much detail, though one suspects it is no longer handled solely by the traditional serials librarian. It may sometimes be delegated to catalogers or systems staff.

\section{Impact on Staff and Departmental Library Structure}

\section{Staff}

Clearly there are enormous differences in workflow between the acquisition and maintenance of print versus electronic journals. In fact, it is arguable that the "print... process bears no resemblance at all to its 90's counterpart, the digital...process" (Duranceau "Beyond..." 92). This has broad implications for library staff: how are they coping with the new medium's divergence from the pre-existing serials work model? Previously, the serials librarian was able to handle most of the work, but now the process is so complicated that it seems as though "a wide variety of staff positions is needed to support electronic resources and maintain the means of accessing them" (Whithers 83).

Some libraries are creating new positions to deal with electronic resources (Whithers 83). At MIT, the position of "Acquisitions Librarian for Digital Resources" was created from an existing vacancy in another department. To the holder of this position was delegated the responsibility to develop electronic products, to facilitate the acquisitions process by defining access options, to determine equipment requirements, to arrange testing sessions, to negotiate licenses, and to collaborate with subject specialists (Dureanceau "Beyond..." 92-93). Duranceau comments that although it was expensive to create this new position, MIT felt it was easier than trying to add on the responsibilities to other positions and radically alter the existing workflow (93). Other new positions 
created as of 1997 at ARL-member institutions include Brigham Young University's “Electronic Access Librarian;” Vanderbilt University's “Electronic Resources Librarian;" Yale University's “Electronic Publications and Collections Specialist;” North Carolina State University’s “Scholarly Communications Librarian;” and University of California at San Diego's “Electronic Resources Unit” (Dureanceau “Beyond...” 94). Some of these positions focus on collections, while others focus more on systems and legal issues (Dureanceau2 93-94).

Another trend is to write new responsibilities into existing library positions (Withers 83; Duranceau 94). Often, serials librarians have electronic resources added to their job description; in the case of American University, the serials position was redefined as “Serials/Electronic Resources Librarian” (Dureanceau “Beyond...” 94). Sometimes acquisitions librarians are asked to assume licensing responsibilities. At George Washington University, the acquisitions librarian now must negotiate licenses along with the electronic reference coordinator (Dureanceau 94). At the University of Wisconsin they changed a traditional acquisitions position to that of "Acquisitions Coordinator" (Whithers 83) and added license negotiation to the job. No matter what approach libraries take, it is clear that the role of the traditional Serials librarian has expanded with the influx of electronic journals. Joni Gomez comments on this in her article, "Human Factors in the Electronic Technical Services," by noting that serials began as a lower staff level job, requiring only the ability to read and mark appropriate Kardex to indicate receipt. With automation came the need for computer literacy; now advanced computer skills are required as well as licensing skills, copyright knowledge, and the ability to communicate with other units (111). 
The libraries that choose to upgrade existing positions rather than add new positions due to budgetary restrictions still must spend money on training their staff in the new tasks. Regardless of the specifics of staffing, electronic resources affect almost all departments at some level, even if it merely involves understanding how to use ejournals. McGinnis and Hemp assert that "often, significant training programs are required for both users and staff before they can use electronic resources effectively" (296). Moothart insists that there must be "a cadre of Internet experts in the organization" for electronic resources to be successfully implemented (138). Gomez notes that many libraries have staff members receive on-the-job training courses, workshops, seminars, or attend educational conferences (110-112).

\section{Departmental Structure}

Some libraries are taking the "add responsibility to existing positions" approach even further by forming teams made up of members from existing departments to handle aspects of electronic journals. This seems appropriate, since "although collaboration between selectors, acquisitions, and cataloging staff has always been important, electronic resources require a different level of attention" (McGinnis/Kemp 296). Duranceau argues that in the digital world, "the lines between acquisitions, collections, and systems work seems particularly fluid and unclear" ("Beyond..." 95). Similarly, Moothart affirms that "the interrelated nature of acquiring, describing, and supporting ejournals may illustrate the blurring of traditional roles of technical services and public services staff" (138). Gomez words it this way: "The explosion of electronic journals and internet resources has contributed to the further breakdown of traditional functional lines of library organization" (107). 
The "team" approach may be the best solution. According to McGinnis and Kemp, "organizations of the $21^{\text {st }}$ century must find a way to make the spontaneous forming and reforming of high-performing multi-disciplinary teams a natural way of working" (298). In a case study of Texas Tech University, the library formed an Electronic Resources Group (ERG) to handle electronic journals. The ERG consists of six members from the following four departments: information technology, reference, acquisitions, and bibliographic services (McGinnis/Kemp 297). The main benefit of the Group is the fact that they make recommendations directly to the associate dean, which reduces the amount of administrative intervention in the process. The ERG processing path for electronic journals consists of a form that must be completed by multiple departments. Initially, it gets filled out for each new product and is given to information technology, where they add technical details and networking information. The form then is forwarded to bibliographic services, where a cataloging decision is made, then the department sends the form back to the selector for final review. The selector forwards the form to acquisitions for ordering. Once the product is received or activated, the form is sent back to bibliographic services and information services (McGinnis/Kemp 300301). Texas Tech University, by using this "cross-functional" team approach, is able to "retain its functional departmental structure rather than embarking on a total reorganization" (298).

Libraries traditionally are organized by function rather than form, but the allencompassing nature of the electronic journal seems to require less specialization and more eclecticism. According to Gomez, several libraries have "undergone reorganization to formally create new less rigid working relationships" (112). Others, as in the case of 
Texas Tech University, have "attempted to increase staff involvement on Committees and task forces" (Gomez 112). According to Bordeianu, et al, a recent trend in ARL libraries is to merge the acquisitions and serials departments, switching even more to functional organization rather than organization according to form (261).

An even newer trend is for departments in technical services to continue to downsize: a few have combined their acquisitions/serials with their collection development/ILL departments (Bordeianu et al 262). At the University of New Mexico, a Technical Services Management Team was formed consisting of people from the acquisitions, serials, cataloging, collection development, and systems departments (Bordeianu et al 263-267). The problems with downsizing departments are discussed in the article. It is expensive to change departmental letterheads and directory information. In addition, internal documents must be updated along with job descriptions. The merger often creates publisher confusion initially, with the result that there are missed serials because they are sent to the wrong address (266-67). On the other hand, the benefits are increased efficiency, reduction of duplication in tasks, streamlined procedures, and the development of new skills for staff members (268-269).

One extreme case of departmental structural change is described in the article “Consortia Building and Electronic Licensing as Vehicles for Re-Engineering Academic Library Services: the Case of the Technical Knowledge Center and Library of Denmark (DTV)" by Lars Bjoernshauge. The DTV was faced with reduced funding, so the staff implemented a radical re-engineering plan in 1998 that replaced the entire collection of paper journals with electronic journals. The DTV developed an Article Database Service based on the INSPEC database, tables of contents for 4,000 journals from SWETS and 
around 300 Elsevier journals. All of the files were stored locally on servers at the library. Next, they built consortia in Nordic countries to add to the Article Database Service content. Then they reduced library paper work by canceling most paper editions to their journals. Staff was reduced considerably; thirteen out of the 80 members were laid off, but this was justified because of the reduction in workload caused by the absence of paper copies, reduced ILL requests, and the fact that the items no longer had to be cataloged into the OPAC. The DTV educated the remaining staff members by leasing computers for them all and having them take Information Technology (IT) courses and participate in an extensive in-house training program (3). The Library also established a new department called the "Contract Management Department" to handle license agreements, calculate economic implications, and consolidate journal subscriptions (6). So far, this plan appears to be working, although naturally the change has caused some turbulence. The Library was able to meet its budget constraints with the money saved from the vanishing paper subscriptions and staff time spent on paperwork. Meanwhile, staff feel they still have access to the most important scholarly journals, and that users appreciate the more convenient retrieval method. Bjoernshauge, who is the director of the Library, feels that if "management is willing to put aside the traditional modes of operation" (7) in favor of new ones, new opportunities will open up.

The verdict is still out on this project. Will it be successful ten years from now? The technology behind electronic journals is still too nascent to say with confidence whether it will be a stable, reliable medium in which to entrust scholarly knowledge. In her article "Electronic Journal Publishing: Observations from Inside," Karen Hunter, the Vice President of Elsevier Science, comments that some libraries are making the transition to 
electronic journals not because they feel the format is ready, but out of financial necessity. For those libraries that cannot now afford both formats, she asks whether "the state of electronic journals and electronic distribution systems [will] be ready" and whether "the work of the researchers [will] be bettered by the switch? (Hunter 5). 


\section{Methodology}

The question of how other research libraries are coping in terms of staffing with the stresses of managing electronic journals is the focus of this study. A survey consisting of seventeen questions was prepared (see Appendix B) and sent to the Head Serials Librarians of institutions who are members of the Association of Research Libraries (ARL).

ARL is a not-for-profit membership organization consisting of the major libraries of North American research institutions. The mission of the organization is to "shape and influence forces affecting the future of research libraries in the process of scholarly communication." ARL has strict membership criteria to ensure that all members are as similar as possible. Most members of ARL are major university libraries. University membership is based on being classified as a Research University I or II in the Carnegie Classification, which is achieved by awarding 50 or more doctoral degrees per year and receiving more than $\$ 15.5$ million in federal support annually. Additional criteria for universities includes similarity of size in number of volumes held, number of volumes added, number of current serials received, total expenditures, and number of staff. The final criteria is the furnishing of strong evidence that the research collection makes a significant contribution. Although most members are university libraries, there are a few 
non-university research library members, such as the New York Public Library, who have demonstrated that their collections have national significance.

The list of ARL members, currently 120 , is available at the web site http://www.arl.org Because institutional research libraries represent some of the primary purchasers of electronic journals and ARL members are leaders in this group, they are representative of libraries dealing with electronic serials issues. The current 120 -member ARL group was chosen as the sampling frame. From the ARL web site and the individual member's institutional library home pages, the email addresses of the Heads of Serials Departments were determined. In some cases, there did not appear to be a clear "serials department," in which case the email address of someone in the acquisitions department who appeared, judging from the organizational chart, to deal with serials was chosen. Ten of the member libraries were excluded from the sample frame because no email addresses for anyone dealing with serials in the library could be determined. Therefore, the final sampling frame was 110 ARL-member professional Serials or Acquisitions Librarians.

An email cover letter was sent out to the 110 librarians with an explanation of the survey and the Uniform Resource Locator (URL) of the actual web-based survey itself (see Appendix A). Two follow-up emails were sent out after the initial cover letter. Submission of a completed survey was taken as consent to participate in the study, and no identifying information was asked so that all responses remained anonymous. The survey itself was created as a web-based form; submitted survey answers were programmed to go automatically into a special, pre-designated file. 
Although all 110 librarians had equal reinforcement and motivation for participating in the survey, only 34 actually responded. This is approximately a $30 \%$ response rate from the 110 people who could have participated. A preliminary investigation of whether or not the number of professional staff members in a library affects how the library acquires and maintains e-journals was conducted. The 34 responses were divided up into three different groups based on the number of professional staff in the library. "Libraries with a small amount of staff" were those with 20-60 professional staff members (16 respondents), "libraries with a medium-sized amount of staff" had 61-100 professional staff members (13 respondents), and "libraries with a large amount of staff" had over 100 staff members (5 respondents). These groups were compared to the average of all three groups to determine any significant differences. In most cases, there were not any statistically significant differences between groups. Because the number of respondents was so small, however, this is an area that can be investigated more substantially in the future.

After the stipulated survey deadline, the data from all thirty-four responses were tabulated. The seventeen survey questions (see Appendix B) were a mixture of multiplechoice nominal, binary, and ordinal data, often giving the librarian the option of choosing multiple answers simultaneously. In addition, one of the questions allowed free response, and throughout the survey space was provided for the librarian to write in comments if he/she chose to. All of the questions attempted to measure how staffing has been affected by the influx of electronic journals. The questions were based on the literature about electronic journals and staffing. The workflow and departmental assignments for print journals was compared to the workflow and departmental assignments for electronic 
journals to determine how libraries are dealing with the new medium. The results were then measured against what is generally known from the literature to determine if the data supports the trends described earlier or if new approaches could be surmised. The electronic journal acquisitions and maintenance process is still diverse and apparently cumbersome for ARL-institutions as the literature suggests. The data were analyzed and depicted in pie graphs and bar graphs to show distribution and percentages.

\section{Results and Analysis}

The first question, "Which departments are involved in one or more aspects of electronic journals?," was asked to determine the range of departments that electronic journal duties encompass. The expectation from the literature review is that the range would have expanded since the traditional print journal was executed by only librarians in collection development, serials, cataloging, and acquisitions departments. The results, displayed in Figure 1, show that, as expected, many additional departments are now involved with the electronic journal medium.

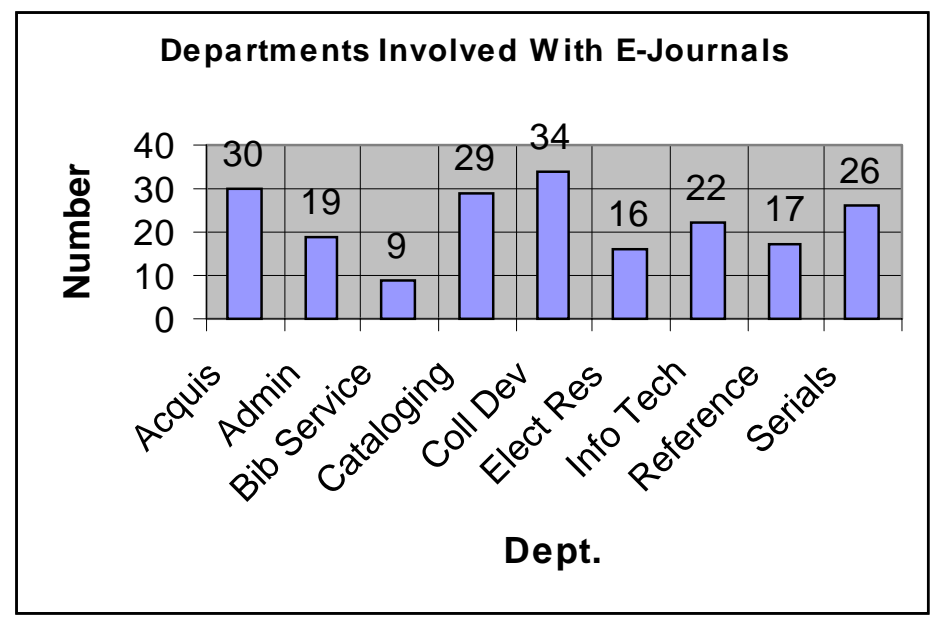




\section{Figure 1 - Departments Involved with E-Journals}

The departments that are most often cited are still the traditional departments that dealt with the print medium in the past: collection development (100\%), followed by acquisitions (88\%), cataloging (85\%), and serials $(76 \%)$. The fact that $24 \%$ of the libraries surveyed did not list "serials" as an involved department is puzzling, but it is probably best explained by a comment from one of the respondents. In this particular library, the "staff that work with print [journals] are not involved with the electronic versions." This suggests that either entirely new positions are being created for the electronic medium rather than the serials librarian expanding the scope of his duties, or that serials departments no longer exist because they have evolved into something else. This possibility was echoed by another respondent, who said "the serials librarian does not deal with electronic resources" in his/her library. Other departments cited as being involved with electronic journals were information technology (65\%), administration $(56 \%)$, reference (50\%), electronic resources (47\%), and bibliographic services $(26 \%)$. It is safe to say that twenty years ago none of these departments were involved with the serials acquisitions and maintenance process. The "electronic resources" department most likely did not even exist!

Questions three and four were used to verify what the literature states is the case: electronic journals require both a higher number of staff members and a greater amount of staff time than print journals require. The results, displayed in Figures 2 and 3, indicate that the number of staff who work with e-journals has increased. Seventy-three percent of the respondents said staff has increased either a lot or a little, while only $6 \%$ 
said it decreased and $21 \%$ said there was no change. Similarly, the amount of staff time spent on electronic journals compared to print journals has increased according to $97 \%$ of the respondents, with only $3 \%$ of the respondents claiming there was a decrease. In this case, $68 \%$ of the respondents were emphatic, claiming that staff time has "increased a lot."

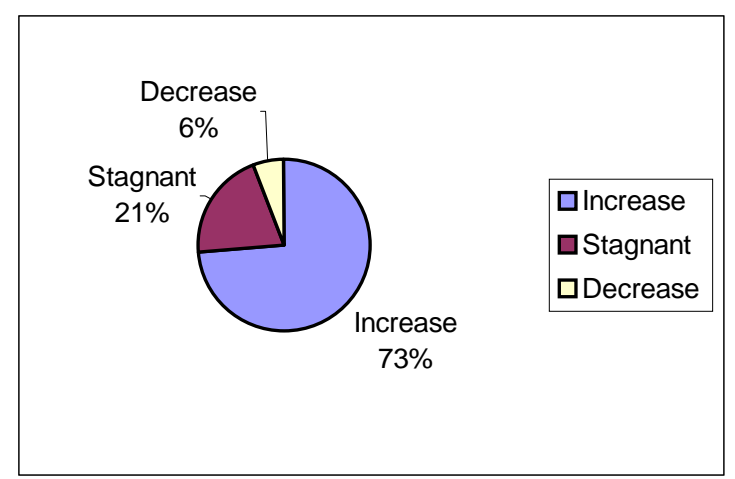

Figure 2 - Number of Staff Who Work with E-Journals Compared to Print Journals

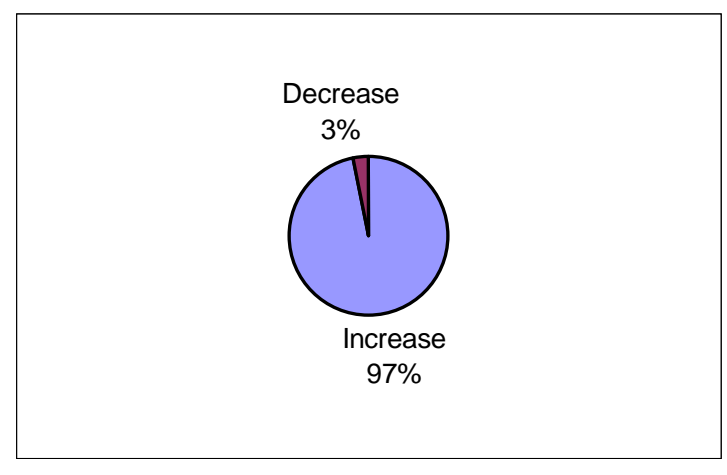

Figure 3 - Amount of Staff Time Spent on E-Journals Compared to Print Journals

Many librarians wrote in comments about how the staff time has grown. One librarian believes "the amount of time spent on the acquisition of e-journals is growing exponentially," while another states that "personally, I feel it has doubled [the] department work load." Still another librarian notes that "the largest portion of staff time spent on e-journals has not been taken from time spent on print journals, but from elsewhere." The most often cited time consumers were licensing and paperwork, as well as URLs and links; the latter are referred to by one librarian as "time-consuming, much more than we used to spend on print journals." However, a few librarians offer hope that eventually this trend will disappear as libraries cease ordering copies of print journals. 
One librarian points out that "in the past the number of [print] titles was increasing...as print journals decrease, I think our staffing will stay stable with a possible decrease." This sentiment was echoed by another librarian, who commented that "eventually, there should be less work." Unfortunately, though, in the present the electronic medium is not stable enough or standardized enough for most libraries to feel comfortable abandoning the print medium.

\section{Changes in Workflow: Who Does What}

\section{Selection}

According to the literature, the selection of e-journals is no longer done solely by collection development librarians. Instead, the process sometimes involves people not only from collection development, but reference, electronic resources, serials, or systems. The survey results in Figure 4 indicate that among ARL members, although collection development is still the most likely department to select e-journals (31), reference departments (12) often get involved as well as the write-in response of "selectors/subject specialists" (10) and electronic resources librarians (7). Rounding out the list are serials (4), committees (3), and systems (1).

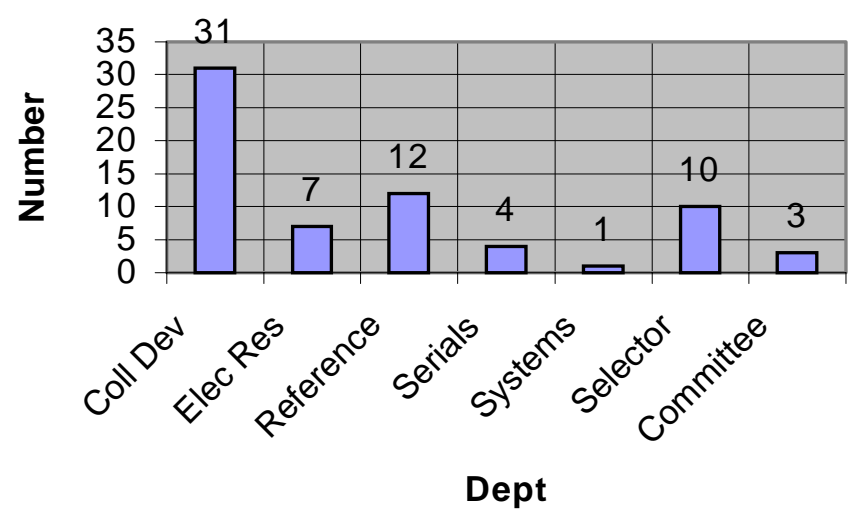




\section{Figure 4 - Selectors of E-Journals}

The literature stresses that often the selections are reviewed, either by a committee or by a department head or director. The committee approach saves a higher number of upper-level staff becoming involved. Question ten of the survey asks who, if anyone, reviews electronic journal selections. The results in Figure 5 indicate that $53 \%$ of the respondents have committees that review selections, while $35 \%$ use an administrator. Only $12 \%$ of the respondents claim their library does not review electronic journal selections. Other departments who received votes were electronic resources (26\%) and systems $(6 \%)$.

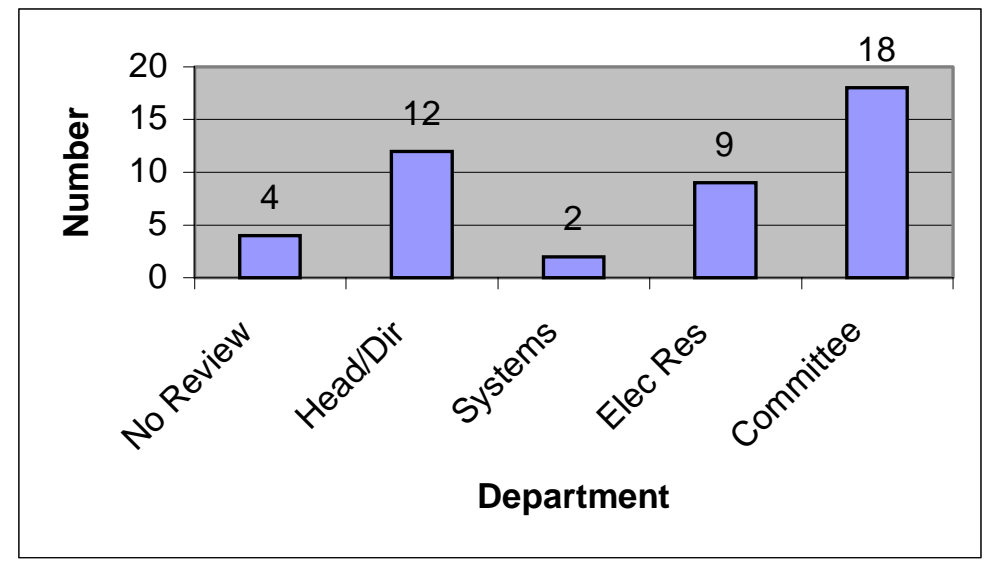

Figure 5 - Who Reviews E-Journal Selections?

There was a difference between the libraries with a small amount of staff and libraries with a medium-sized amount of staff that is worth remarking upon. As Figures 6 and 7 indicate, the libraries with a small amount of staff appear to rely less on committees than the libraries with a medium-sized amount of staff (44\% versus $62 \%)$. 


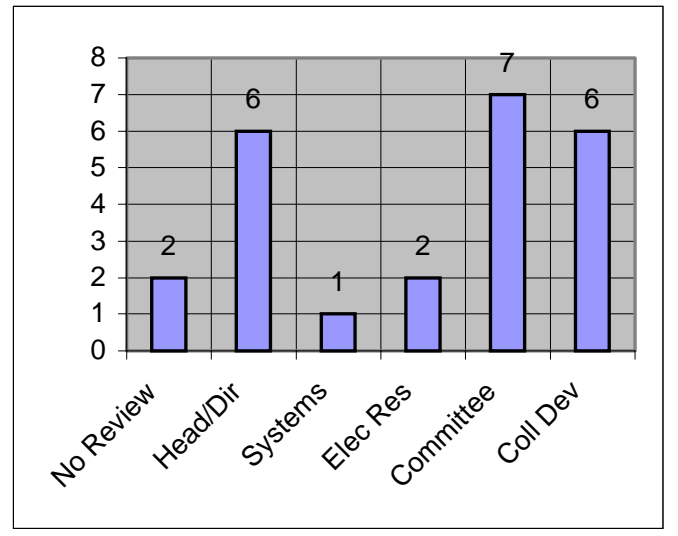

Figure 6 - Reviewers of E-Journal Selections in Libraries with Smaller Amount of Staff

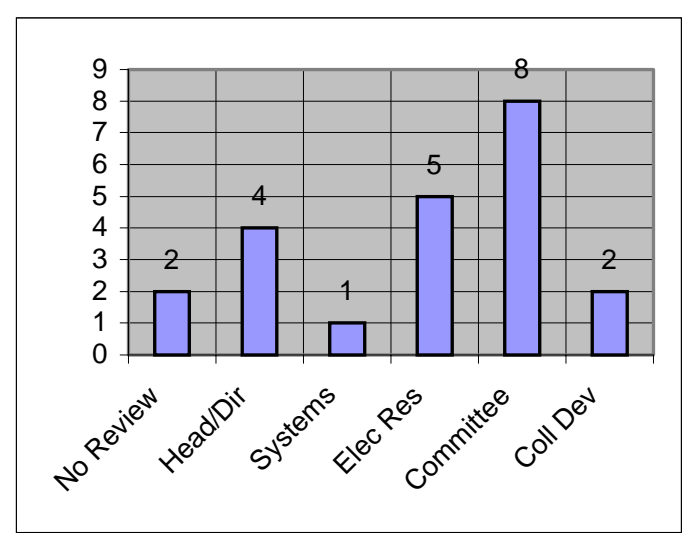

Figure 7 - Reviewers of E-Journals Selections in Libraries with MediumSized Amount of Staff

Instead, libraries with less staff rely more on collection development librarians (38\%

versus $15 \%$ ), whereas libraries with a medium-sized amount of staff rely more on electronic resources (38\% versus $13 \%$ ). The director/head category was only slightly more for libraries with less staff (38\% versus $31 \%$ ). This suggests that perhaps libraries with fewer staff do not have specialized "electronic resources" departments, and that they are relying more on existing staff to take on new roles. One librarian from a library with a smaller amount of staff commented "We are looking at forming an electronic resource team. But since we can't add staff and are still mandated to maintain traditional services it's a big problem about where the staff will come from." A few of the libraries with less staff commented that they only reviewed selections if they were received from large aggregators and thus required special examination. Question 10-B asks those 53\% who said a committee reviews selections to specify who was on the committee. As Figure 8 
indicates, reference is the most-often cited (83\%) department, followed by acquisitions (72\%), systems (61\%), and electronic resources $(50 \%)$. This is reasonably consistent with the literature.

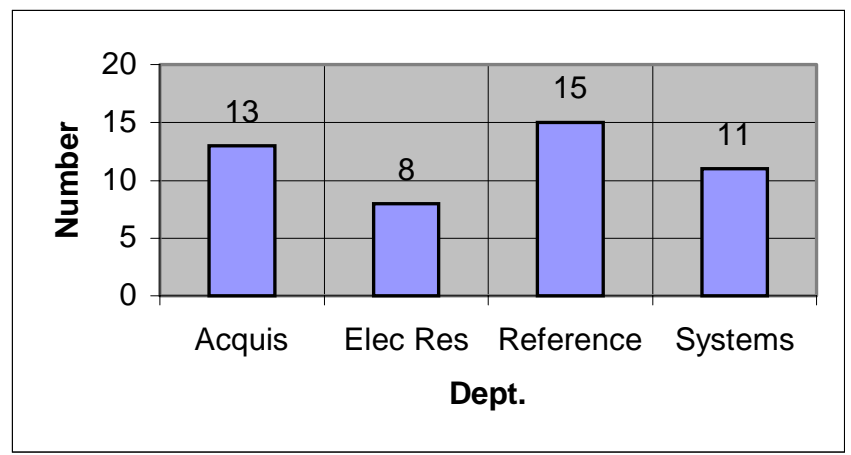

Figure 8 -- Special Selection Review Committee

\section{Ordering and the License Agreement}

As indicated by the literature, because in most cases an electronic journal is accessed rather than owned, "ordering" now involves a license agreement with explicit legal terms. These license agreements are causing a higher number of professional staff to become involved in the ordering process. Question nine of the survey asks if

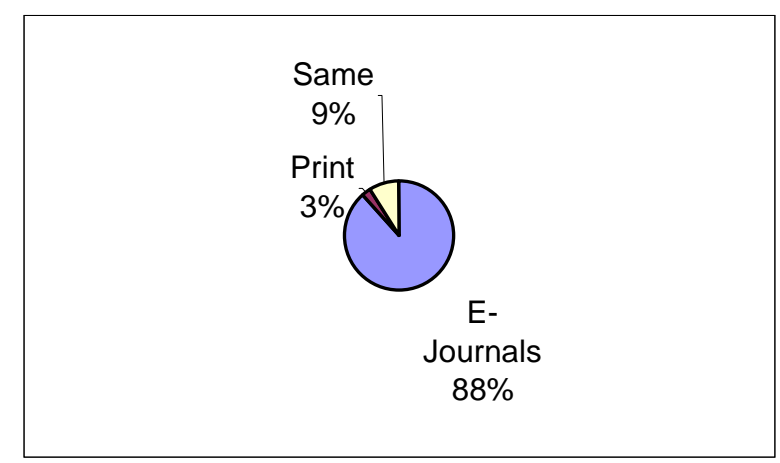

Figure 9 - Number of Professional Staff Involved with Ordering Process 
electronic journals or print journals require a higher number of professionals to become involved in the ordering process. Predictably, an overwhelming $88 \%$ of the respondents feel that electronic journals require the higher number of professionals, while a scant $3 \%$ feel that print journals do and nine percent feel there is no difference in the number of involved professionals (see Figure 9).

Many libraries even require special legal consultants to help them negotiate license agreements since librarians are often baffled by the legal jargon that makes up the license. Question thirteen asks the librarian if there are any legal consultants who help with the licenses in their library. The majority claim they do have legal consultants: Figure 10 indicates that $65 \%$ of respondents said yes, while $35 \%$ said no.

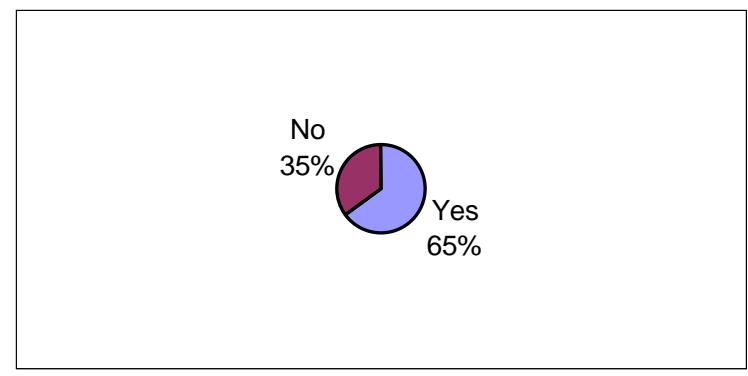

Figure 10 - Do You Have Any Legal Consultants Who Help with Licenses?

All five of the libraries with larger staff sizes do have legal consultants, while $62 \%$ of the libraries with a medium-sized number of staff do and only $56 \%$ of the libraries with a smaller number of staff. Although the samples are small, this suggests there may be a pattern: the libraries with more staff have bigger budgets and order more e-journals, so they require legal consultants. On the other hand, the libraries with fewer staff do not order as many and probably get their e-journals more from memberships with consortia; this means the consortia must negotiate the licenses rather than the library itself. 
Question twelve asks directly who negotiates license agreements for the library. The results support the theory about why larger libraries have legal consultants. The literature suggests that in some cases negotiation is done by librarians, either alone or on committees involving collection development, acquisitions, subject specialist, or systems departments. Other libraries let consortia or administrators do the negotiating. Overall, the three group totals indicate, as displayed in Figure 11, that there is a hodge-podge of different departments doing the negotiating. The acquisitions department was cited most often with $35 \%$, followed closely by administrators and the collection development department with $32 \%$ of the respondents' votes apiece. Next were electronic resources (24\%), consortium (21\%), and serials (18\%). Reference (6\%) and systems (3\%) got surprisingly few mentions, while cataloging failed to get any votes at all.

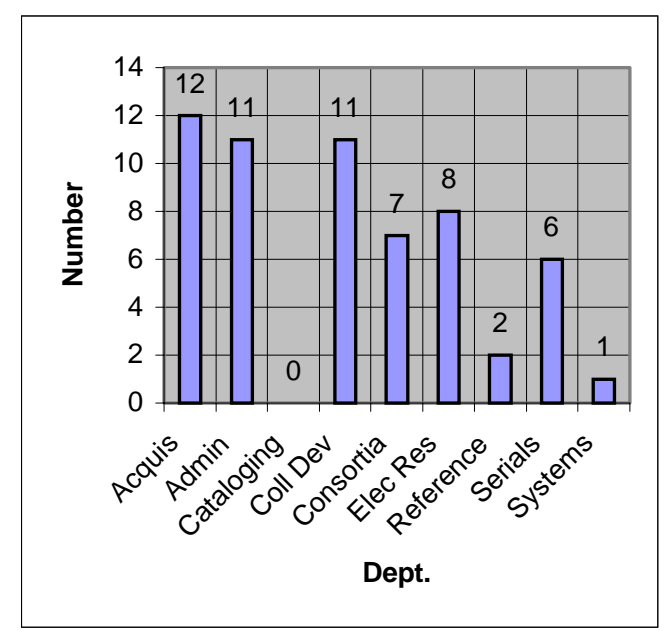

Figure 11 - Who Negotiates License Agreements?

When the three groups are separated, the libraries with the largest number of staff have a $0 \%$ consortia rate, though admittedly there are only five libraries in this sample group. Instead, they report that acquisitions and electronic resources departments usually do the license negotiation, while administrators got zero votes. Conversely, as indicated by 
Figures 12 and 13 below, libraries with the smallest number of staff report a higher rate for consortia (31\%) than either of the other groups. These libraries also report a higher rate of acquisitions department involvement (44\%). Libraries with a medium-sized number of staff, on the other hand, report a higher rate of participation from administrators (46\%) than smaller libraries (31\%). Another interesting comparison is the amount of serials librarian involvement between the small and medium-sized groups during licensing negotiation. The serials librarian is much more involved in the negotiations in libraries with a medium-sized number of staff $(31 \%)$ than in libraries with a small number of staff $(6 \%)$. This is possibly because libraries with fewer staff do not

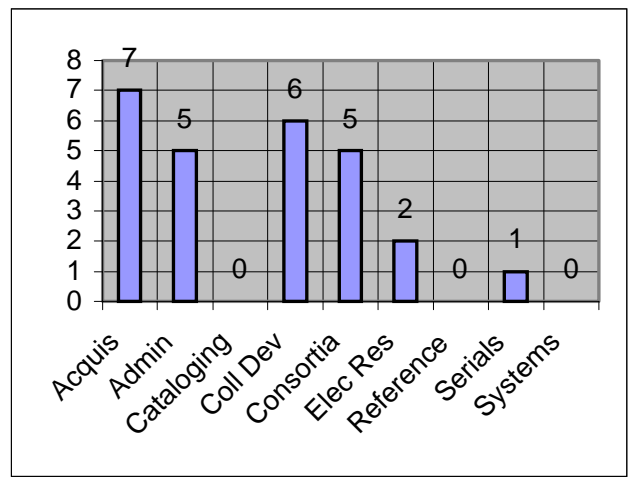

have as much of their own negotiating to do; they let consortia and administrators handle it for the most part. When they must have a librarian negotiate, they relegate the duty more often to acquisitions or collection development.

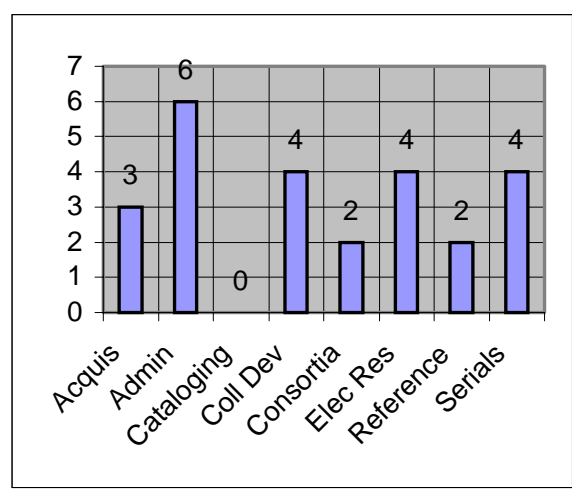

Figure 12 - Who Negotiates
Figure 13 - Who Negotiates 


\section{Licenses in Libraries with Medium-Sized Amount of Staff? \\ Licenses in Libraries with Small Amount of Staff?}

Interestingly, one respondent commented that "collection development has taken the lead in capturing and promoting electronic journals" rather than serials librarians.

Question eleven asks the librarian if his/her library has a standardized procedure for negotiating license agreements or if each electronic journal is still treated as a separate case. The literature announces that there is little standardization in the procedure because each journal is so different and the medium is still so unsettled. The question was asked to see if this has changed, since most of the literature was written a year or two ago. Has there been great progress towards integrating electronic journal license negotiations into the regular library workflow? Does it now take less time and require less labor?

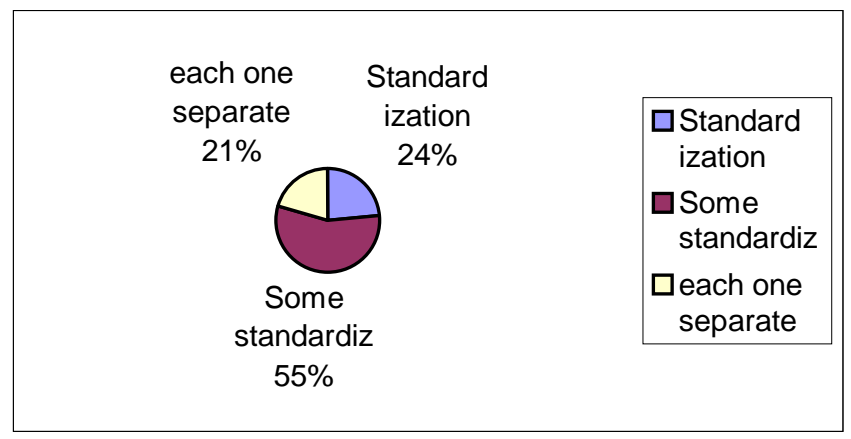

Figure 14 - Is There a Standardized Procedure for Negotiating License Agreements?

The results, shown in Figure 14, imply there has been change in this area.

Standardized procedure for license negotiation am ong small libraries? Each one separate $6 \%$ Standard ization

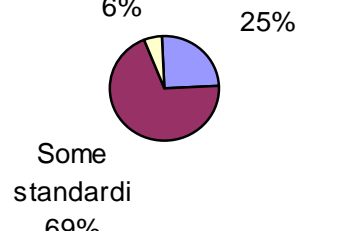

Standardized license negotiation among medium-sized libraries? Standard ization $15 \%$

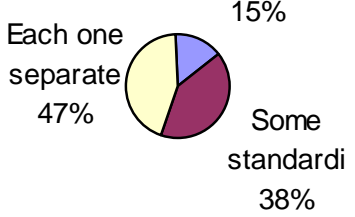




\section{Figure 15 - License Negotiation Among Libraries With Small Staff}

Figure 16 - License Negotiation Among Libraries With Medium Staff

Although only $24 \%$ of the respondents report complete standardization, $55 \%$ report some standardization among e-journals with similar access criteria. Therefore, $79 \%$ report at least some standardization in the process. This appears to be a substantial amount of progress if this small sampling of ARL institutions is any indication. Only 21\% report that each license is negotiated separately. Libraries with a large number of staff did not report any instances where each journal is negotiated separately. Libraries with a medium-sized number of staff report the least amount of standardization; $47 \%$ of those respondents claim each journal is still negotiated separately and only $15 \%$ said there is complete standardization (See Figure 16). Libraries with fewer staff, on the other hand, report only a $6 \%$ instance of each journal being negotiated separately; $94 \%$ of the respondents said there is at least some standardization, although $69 \%$ did admit it was only "some" standardization (see Figure 15).

\section{Maintenance of E-Journals: Archiving, Bibliographic Control \& Updating}

As the literature reports, back issues of e-journals are troublesome because of the

"lease rather than own" nature of the medium. Are publishers guaranteeing access to back issues if a library cancels their subscription? What if they cease publishing a particular journal, will the web site be maintained? Is the web site stable and able to 
eschew any technological pitfalls or adjust itself should technology advance? Question fourteen was asked to see if ARL members are taking on the responsibility of archiving e-journals themselves, thus adding to their already-overburdened workload, or if

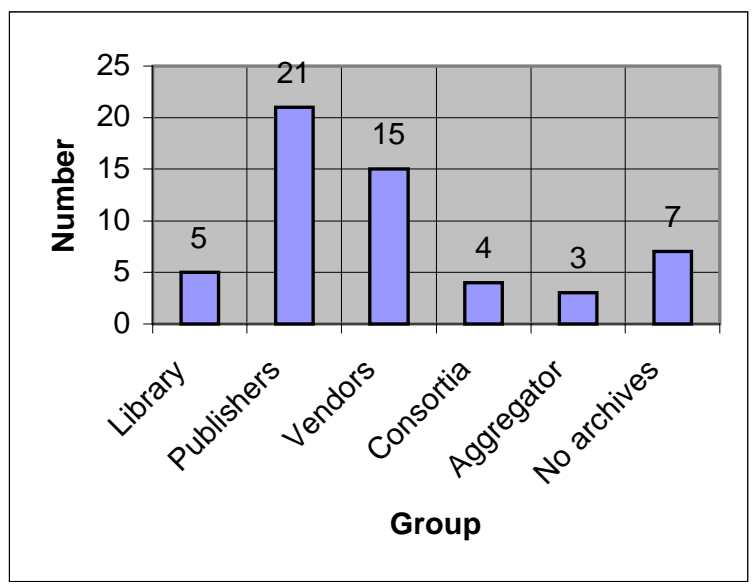

publishers, vendors, or consortia are archiving the majority of e-journals. The literature suggests that only about $25 \%$ of libraries are archiving e-journals, instead allowing the responsibility to be taken over by vendors and aggregators. The results, displayed in Figure 17, show that among the libraries who participated in this survey, even fewer libraries are archiving. Fifteen percent of the responding libraries said they archive ejournals themselves, and most of these are libraries with a large staff. Instead, archiving is usually done by publishers (62\%) and vendors (44\%).

\section{Figure 17 - Who Archives Back Issues of E-Journals?}

It is slightly alarming that $21 \%$ of the libraries report their e-journals are not archived at all! Also, it is surprising only $12 \%$ report some archiving being done by consortia, and only $9 \%$ report that aggregators are doing it. These results signal a break in the library's traditional role of library acting as depository for all scholarly information. 
Question fifteen asks how the library maintains bibliographic control over their electronic journals. The literature suggests that almost all libraries (93\%) are creating separate web pages for their electronic journals, while $63 \%$ of the libraries are creating direct links to e-journals through their OPACs. Since there is a substantial overlap here, it suggests many libraries are doing both. The results of this survey, exhibited in Figure 18 , show that more libraries $(94 \%)$ are now utilizing the OPAC direct link method, while $74 \%$ are mounting separate web pages. A $65 \%$ overlap between the two shows that $65 \%$ of the libraries use both methods.

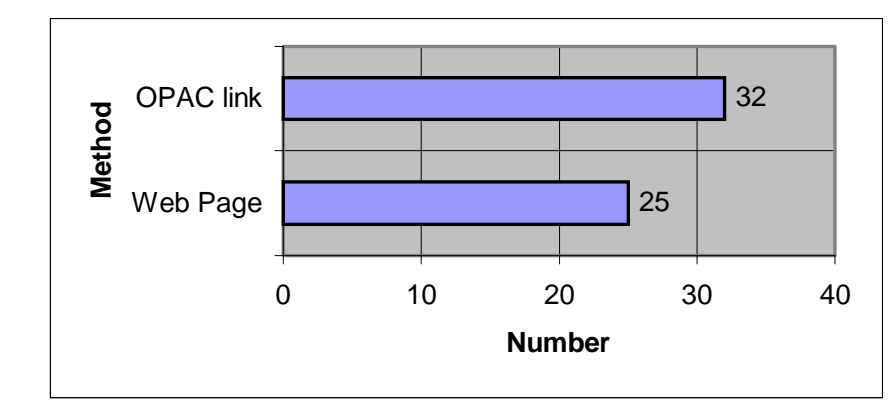

Figure 18 - Bibliographic Control Over E-Journals

Although an overwhelming majority (94\%) of libraries with a small number of staff have OPAC links, only $56 \%$ have web pages. It may be a question of workload: a few of these librarians commented that they "discontinued the separate web page as too labor intensive." Part B of question fifteen asks which department is responsible for maintaining bibliographic control, whether it is via OPAC links, web pages, or both. The results, displayed in Figure 19, reveal that the majority of libraries said the cataloging department (53\%), followed by serials (24\%) and systems $(21 \%)$. 


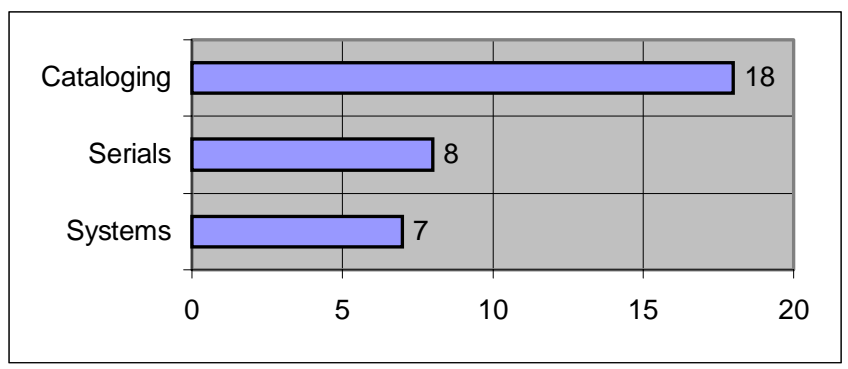

\section{Figure 19 - Dept. Responsible for Bibliographic Control}

While these two methods (OPAC and web pages) are still the primary means of bibliographic control, some of the librarians talked about the future. One librarian talked about wanting "a dedicated gateway interface with keyword searching for electronic resources only" as well as the OPAC links. Another disclosed that his/her library is "in the process of creating a web database that will take records from the online catalog and create a web interface." Still another librarian said "we are putting our efforts into direct full text links from citation databases with URL links from catalog records as second choice" because of the user preference for full-text e-journal access.

The literature suggests that both link maintenance software and user feedback are being used to update links and fix access problems in addition to actual librarians. Question 16 was asked to see if libraries are increasing their usage of these methods in order to lessen the workload. The results of this survey, exhibited in Figure 20, suggest that the majority of libraries are using one of these two methods. Twenty-nine percent of the libraries use link maintenance software, while $29 \%$ rely primarily on user feedback. Of the $42 \%$ who use librarians primarily, catalogers got the most votes followed by information technology, electronic resources, and collection development. 


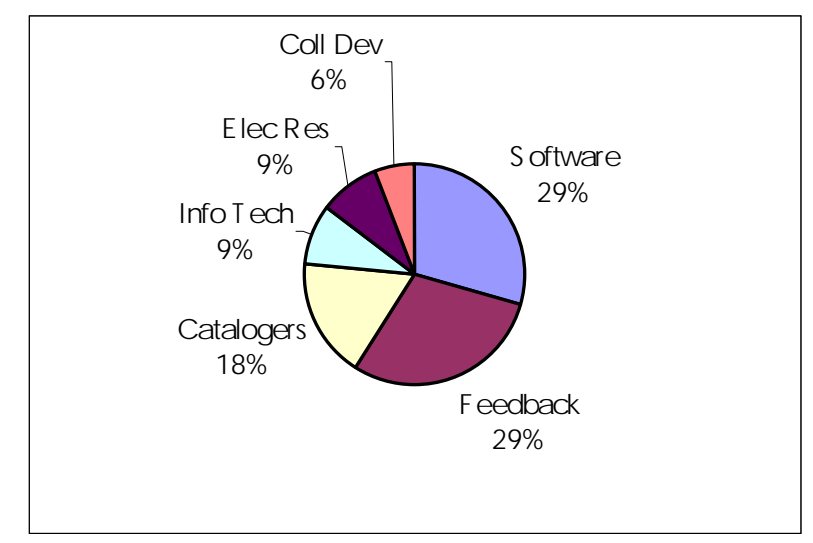

Figure 20 - How Do You Update E-Journals?

\section{Expansion of Existing Positions}

The literature discusses how some libraries, rather than creating brand new positions for electronic journal management, are expanding previous positions through training or job reclassifications. Because the serials librarian is a potential candidate for a job reclassification or expansion, question five of the survey asked him/her if there was an upgrade in the position over the past year because of more duties related to electronic journals. The results, displayed in Figure 21, show that most have not had upgrades; seventy-six percent report they have not, while only $18 \%$ report an actual upgrade and $6 \%$ said it was discussed, but resulted in no action. 


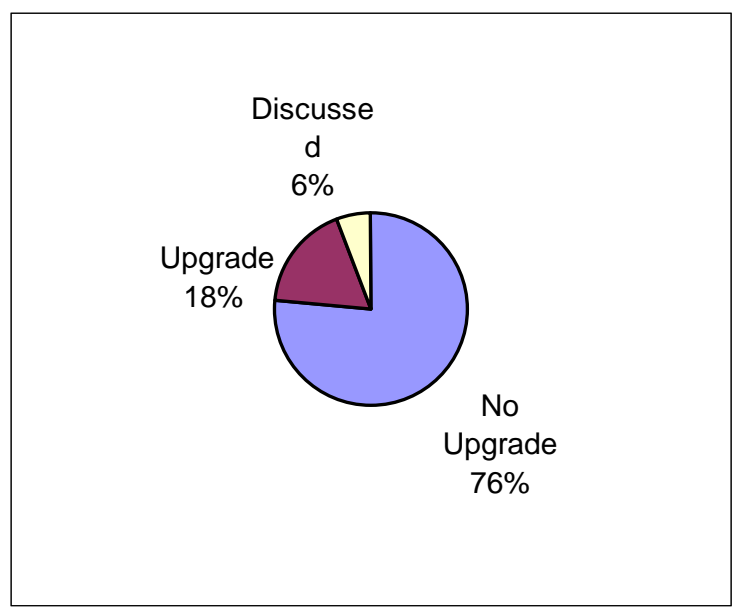

Figure 21 - Number of Upgraded Job Descriptions or Classification Levels for Serials Librarians

Question six attempted to determine what kind of extra training serials librarians are getting to assist them in dealing with e-journals. The results in Figure 22 indicate that

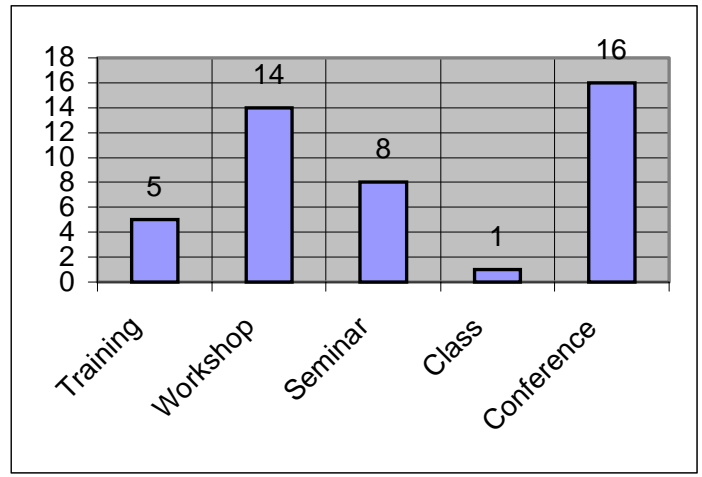

Figure 22 - Supplemental Help With E-Journals

conferences are the most popular means of supplemental tutorials (47\%), closely followed by workshops (41\%). Seminars were mentioned by $24 \%$ of the respondents, 
while training $(15 \%)$ and classes $(3 \%)$ are seldom used. Twenty-nine percent of the respondents claim they have received no supplemental training at all; most likely, as one respondent wrote in, it is because they "learned on [their] own."

\section{New Positions and Departmental Structure}

Question two of the survey asks what new positions, if any, the library has created in the past two years to help with the acquisitions or maintenance of e-journals. Figure 23 shows the total results, divided by the department of the new position(s).

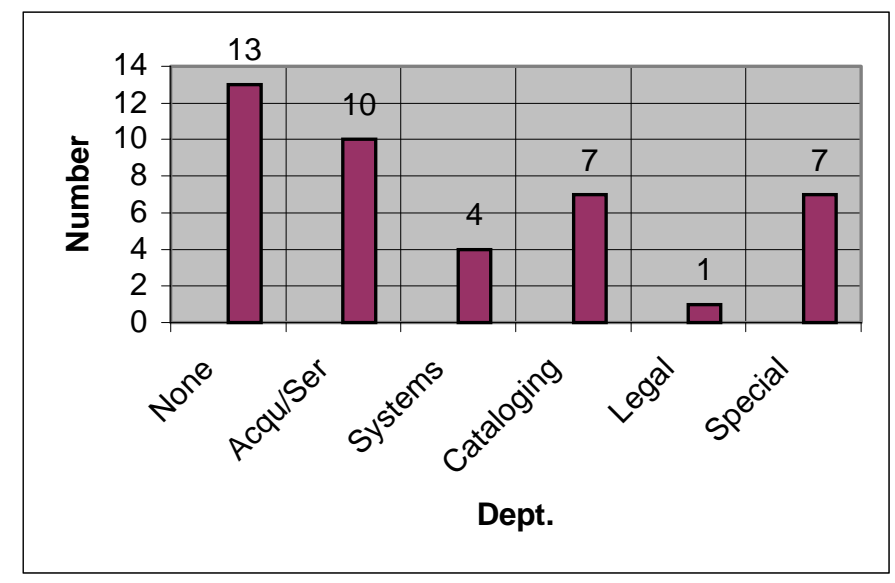

Figure 23 - New Positions Created as a Results of E-Journals

Because so few serials librarians had their position upgraded, one would expect there to be many new positions created to handle e-journals. The results show this is not entirely the case. Thirty-eight percent of the libraries surveyed state no new positions have been created in relation to e-journals over the past two years; however, $62 \%$ of these are libraries with a smaller amount of staff. Respondents in libraries with a medium-sized amount of staff only report a $23 \%$ rate of no new positions. The most often cited department for new positions is acquisitions and/or serials (29\%), followed by cataloging (21\%) and specialty e-journal positions that deal with more than one departmental 
function $(21 \%)$. Libraries with a medium-sized number of staff have the majority of these "specialty" positions; they account for $86 \%$ of the total $21 \%$. In some cases libraries are creating entirely new departments; one librarian commented that "during a re-organization, several units that handled print and e-journals were combined into a new department." Also mentioned as departments with new positions were systems (12\%) and legal (3\%) positions. Tables 1-3 show the new positions in more detail, broken down by the size of the library staff.

\begin{tabular}{|l|l|}
\hline Electronic Resources Support (Acquis) & Serials (pt electronic journal maintenance) \\
\hline Library Gateway Administrator (Sys) & Catalogue Maintenance-Elect Resources (Cat) \\
\hline Info Tech \& Support (Sys) & Electronic Produces Access Librarian \\
\hline Electronic Data Specialist (Acquis/Ser) & Electronic Resources Cataloger (Cat) \\
\hline Licensing Coordinator (Legal) & Electronic Resources Librarian \\
\hline
\end{tabular}

\section{Table 1 -- New Positions Created for E-Journals in Libraries With a Small Staff over the Past 2 Years}

\begin{tabular}{|l|l|}
\hline Electronic Information Librarian & Digital Acquisitions Coordinator (Acquis) \\
\hline Electronic Resources Librarian (Acquis) - 3 & Electronic Resources Coordinator (Sys) \\
\hline Serials Acquisitions Professional (Acqu/Ser) & Digital Library Coordinator (Sys) \\
\hline Cataloging of Electronic Resources (Cat) & Digital Resources Acquisitions Librarian \\
\hline Head, Electronic Resources Section & Serial Electronic Resources Librarian (Acq) \\
\hline Serials \& E-Resources Department (Ser) & Electronic Resources Technical Manager (Acq) \\
\hline E-Resources Specialist & Web Librarian (Cat) \\
\hline Electronic Materials Cataloger (Cat) & Electronic Products \\
\hline
\end{tabular}

Table 2 -- New Positions Created for E-Journals in Libraries with a Medium-Sized Staff Over the Past 2 Years

\begin{tabular}{|l|l|l|}
\hline $\begin{array}{l}\text { Assistant Head of Digital Library } \\
\text { Services }\end{array}$ & Cataloger/Biller & Basic Searcher (Acq) \\
\hline
\end{tabular}




\section{Table 3 - New Positions Created for E-Journals in Libraries with a Large Staff Over the Past 2 Years}

Question seven of the survey attempts to gauge how the departmental structure of the library is changing in order to accommodate e-journals. The literature suggests downsizing in technical services departments has occurred in general, with specific acquisitions and serials departmental merging. A newer trend, according to the literature, is for acquisitions/serials departments to merge with ILL/collection development departments. The survey results only give a little evidence that there is acquisitions/serials merging, and none that there is the latter. The wording of the question did not imply that the departmental changes have to be related to e-journals; rather, it simply asked the librarian to "indicate how the following technical services departments have changed over the past 18 months." The six departments examined were acquisitions, serials, collection development, ILL, cataloging, and systems. The librarian was asked to determine, for each department, whether a merging, downsizing, expansion, abolishment of a section, creation of a new section, or creation of new positions had occurred. The results, displayed in Table 4, reveal that there is not an overwhelming amount of change in the surveyed libraries' departmental structures.

\begin{tabular}{|l|l|l|l|l|l|l|}
\hline & ACQUIS & SERIALS & $\begin{array}{l}\text { COLL } \\
\text { DEV }\end{array}$ & ILL & CAT & SYSTEMS \\
\hline $\begin{array}{l}\text { Merged with } \\
\text { another } \\
\text { Department }\end{array}$ & 7 & 6 & 1 & 1 & 1 & 2 \\
\hline $\begin{array}{l}\text { Downsized a } \\
\text { section }\end{array}$ & 6 & 3 & 0 & 1 & 4 & 0 \\
\hline $\begin{array}{l}\text { Expanded } \\
\text { on a section }\end{array}$ & 4 & 2 & 2 & 2 & 4 & 5 \\
\hline $\begin{array}{l}\text { Abolished a } \\
\text { section }\end{array}$ & 0 & 3 & 0 & 0 & 0 & 0 \\
\hline $\begin{array}{l}\text { Created a } \\
\text { new section }\end{array}$ & 2 & 2 & 2 & 1 & 3 & 2 \\
\hline
\end{tabular}




\begin{tabular}{|l|l|l|l|l|l|l|}
\hline $\begin{array}{l}\text { Created new } \\
\text { positions }\end{array}$ & 5 & 6 & 5 & 1 & 7 & 12 \\
\hline
\end{tabular}

Table 4 - Departmental Activity

For the first category, "merged with another department," the only significant activity is in the serials and acquisitions departments, which supports what the literature says. Twenty-one percent of the libraries surveyed report their acquisitions department has experienced a merger in the past eighteen months, while $18 \%$ of the libraries report their serials department has merged. The next category, "downsized an existing section," also has the acquisitions department in the lead with $18 \%$, followed by the cataloging department with $12 \%$ and the serials department with only $9 \%$. The third category, "expanded an existing section," has systems in the lead with $15 \%$, followed by both acquisitions (12\%) and cataloging (12\%). It must be noted, however, that all of the instances of the catalog department expansions are libraries with a small number of staff. The only department that got any votes for the fourth category, "abolished a section," is the serials department with 9\%. The fifth category, "created a new section," only occurred in the cataloging department (9\%). The last category, "created new positions," showed the most activity. The systems department in 35\% of the libraries surveyed has created new positions, while $21 \%$ of the cataloging departments have new positions, $18 \%$ of the serials departments, and $15 \%$ of both the acquisitions and collection development departments.

Exactly how much all of the departmental change is related to e-journals is unknown, but departments are noticeably becoming less clearly defined and more dynamic. Because e-journals affect so many librarians, increased communication between departments is essential, regardless of the library's individual approach to staffing or workflow. Some of the survey respondents commented on the necessity of collaboration; 
one librarian from a smaller library complained that "lack of communication among all of the people dealing with electronic resources is a major problem," while another from a medium-sized library said "e-journals are forcing a new level of cooperation to emerge between technical services and public services." 


\section{Conclusions}

\section{Limitations}

The most obvious limitation of this study is the fact that out of the 110 ARLinstitutions who were surveyed, only $30 \%$ responded to the survey. This appears to mean that one should not make too many generalizations from such a small number of respondents. However, because of the strict criteria exercised on ARL member institutions to ensure similarity in size, allocated funds, number of degrees awarded, and significance of the collection, the members who responded cannot be entirely dissimilar from the group as a whole. Therefore, there is no reason to suspect a substantial bias in the responses simply because the response rate is low. This also applies to the possibility of a non-response bias. Even though the type of librarian and his/her place of employment undoubtedly influences whether or not he/she desires to respond on a personal level or is able to respond based on time pressures and the environment of the institution, the libraries should not differ from one another drastically.

The survey is not based on the investigator's observations but is instead self-reporting, which eliminates the possibility of "observer bias." However, it does offer the possibility of a participant bias. Participants may give false answers due to a lapse in memory, because they do not know the answer, but feel compelled to estimate, or because some answers seem more socially acceptable. Also, because some of the survey questions are closed questions and only allow for one answer, it is possible in some cases that the real answer is not a choice, and the respondent must choose an inaccurate one instead. Throughout the survey, there are places for free-text comments to try to compensate for 
this. Two of the questions use an arguably ambiguous scale with the following two options: "increased a lot" and "increased a little." Even if individual scales differ, though, on what constitutes "a lot" or "a little," the averages probably remain the same in the end.

\section{Significance of Results}

As expected, the ARL respondents report that electronic journals are requiring more inter-departmental involvement, staff time, staff members, and a larger amount of administrative involvement than their print journal predecessors. An overwhelming majority of the respondents report that e-journal selections are reviewed, either by a committee or an administrator.

ARL respondents report a much higher rate of standardization in their procedures for negotiating license agreements than the literature. Seventy-nine percent said there is at least some standardization among electronic journals with similar access criteria. If the survey respondents are representative of research institutions as a whole, this is an interesting disclosure because it means libraries are finding a way to reduce the seemingly unique characteristics of e-journals into manageable categories that can be integrated into their workload. However, that does not mean it is not costly; more than half of the ARL institutions responding have legal consultants assisting them with licensing negotiation.

Libraries are not archiving e-journals themselves, according to the survey results. Instead, publishers and vendors are taking on the responsibility. This marks a change, 
since traditionally libraries have always taken complete control over print journals. Although it is a positive change since it lightens the librarian's workload, does the shift mean libraries are giving up access, and thus power? The question of who is archiving ejournals should be revisited in a few years, after the electronic journal medium has become more stable. The survey results show that almost all of the ARL respondents now exercise e-journal bibliographic control by providing links in their OPACs, showing that their technical systems are up to this task. Many also provide separate e-journal web pages, although libraries with a small number of staff do not implement this method as much because it increases the workload too much. Other workload relievers that are being used to maintain e-journals are link maintenance software and user feedback; this alleviates the strain on catalogers, who otherwise are usually given the task.

Surprisingly, the majority of respondents (serials librarians) have not had a job upgrade as a result of increased e-journal duties. However, although twenty-nine percent received no training to help them manage e-journals, the majority of respondents have, usually in the form of conferences and workshops. The respondents report some new positions created to deal with e-journals, usually in acquisitions, serials, or cataloging departments, as well as some "specialty" positions that have interdepartmental, holistic functions. There is slight evidence to support the literature's claim that acquisitions and serials departments are merging and/or downsizing. There is more evidence that suggests systems departments are expanding and adding new positions, not surprising since libraries are becoming increasingly dependent upon technology. In addition, a small percentage of new positions were added in cataloging, serials, acquisitions, and collection development departments. 
E-journals represent only a small part of the technological revolution in libraries.

However, e-journals appear to be a contributing factor to the major structural changes taking place in libraries and the increasingly unclear boundaries between departments. 


\section{Appendix A}

\section{EMAIL TO SURVEY PARTICIPANTS}

Dear Serials/Acquisitions Librarian:

I am inviting you to participate in a study that examines how academic libraries are meeting the challenges of electronic journals in terms of staffing. You are being asked to participate because you are a Serials Librarian at an ARL-member institution. As you know, there is much discussion within our profession about the changes brought on by the new medium of the electronic journal. The goal of this research is to better understand how staffing has been affected by electronic journals and what implications this has for the future organizational structure of the library.

If you decide to participate in this survey, and I hope you do, please go to the URL http://www.ils.unc.edu/ gards/survey.html and answer the survey questions that appear. I would appreciate a returned response by no later than June 14, 2000. I have tried to keep the questions short so that completing the survey will only require about 10 minutes of your time.

All information you provide will be completely anonymous and confidential. No identifying information has been placed on this questionnaire. However, once you have submitted the survey, I will be unable to withdraw it from the data pool. Submission of the survey will be taken as indication of your consent to participate in this project.

The Academic Affairs Institutional Review Board (AA-IRB) of the University of North Carolina at Chapel Hill has approved this study. If you have any concerns about your rights in this study you may contact the Chair of the AA-IRB, David A. Eckerman, at CB \#4100, 201 Bynum Hall, UNC-CH, Chapel Hill, NC 27599-4100, (919) 962-7761, email aa-irb@unc.edu.

If you have any questions or concerns regarding the survey itself, you may contact Susan Gardner at gards@ils.unc.edu or by phone at (919) 969-2982. You may also contact the adviser for this project, Evelyn Daniel, at daniel@ils.unc.edu or by phone at (919) 962-8062.

Thank you in advance for your participation in this survey. I know your time is valuable. The results of this survey will be aggregated and incorporated into a Master's paper for the University of North Carolina at Chapel Hill's School of Information and Library Science. If you wish, I would be happy to send you an executive summary of my results.

Sincerely, 
Susan J. Gardner, Principal Investigator

School of Information \& Library Science

University of North Carolina at Chapel Hill 


\section{Appendix B}

\section{Survey}

Electronic Journals Survey

1) In your library, which departments are involved in one or more aspects (selection, acquisitions, licensing negotiations, bibliographic control, maintenance, or renewal) of electronic journals?

Acquisitions

Administration $\square$

Bibliographic Services $\square$

Cataloging $\square$

Collection Development

Electronic Resources

Info Technology/Systems

Reference $\square$

Serials

Other (please specify)

2) What new positions, if any, has your library created in the past two years to help with the acquisitions or maintenance of electronic journals?

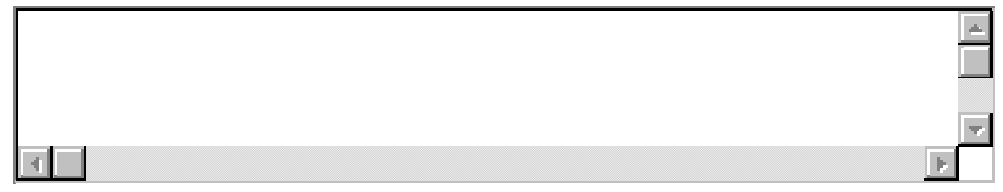

3) The literature reports many changes in staff patterns as a result of electronic journals. Compared to the number of staff members who worked with print journals before your library started receiving electronic journals, have the number of staff who work with electronic journals:

Increased a lot ${ }^{\circ}$ 
Increased a little

Not increased 0

Decreased 0

4) Compared to the amount of staff time previously spent on print journals, has the amount of staff time spent on electronic journals:

Increased a lot $\odot$

Increased a little

Not increased

Decreased ${ }^{\circ}$

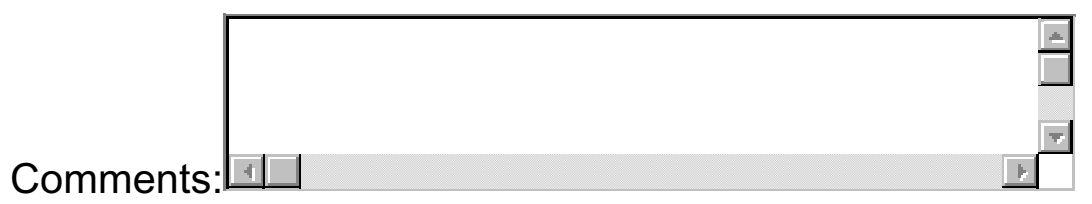

5) Has your job description or classification level been upgraded over the past year because you are taking on more duties that are related to electronic journals?

Yes ${ }^{\circ}$

No

Discussed (no action)

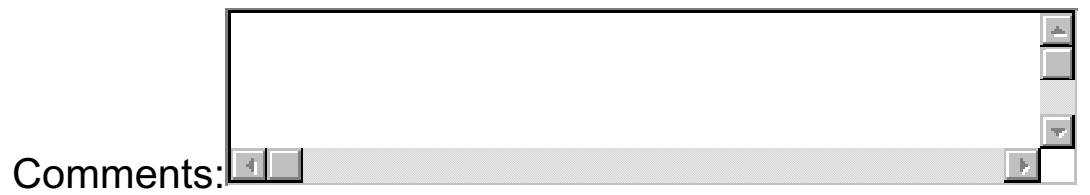

6) Have you had any of the following to help you deal with electronic journals over the past year:

Extra training A workshop A seminar A class A conference 
Comments:

7) Please indicate how the following technical services departments have changed over the past 18 months:

\section{Acquisitions Serials \\ Collection Development \\ ILL Cataloging Systems}

Merged with another Dept.

Downsized an existing section

Expanded an existing section

Abolished an existing section

Created a new section

Created new positions
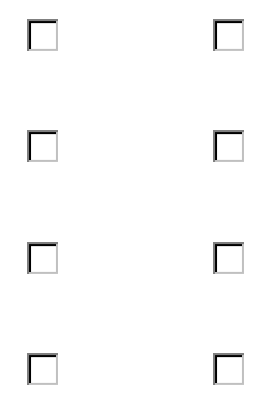

\ulcorner

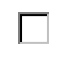

$\Gamma$

8) Who selects electronic journals for your library?

Collection Development Librarian $\square$

Electronic Resources Librarian $\square$

Reference Librarian

Serials Librarian

Systems Librarian $\square$

Other (please specify)

9) Do electronic journals or print journals require a higher number of professionals to become involved in the ordering process:

Electronic journals ${ }^{\circ}$

Print journals 0

Both require the same number of upper-level staff members 10) Who, if anyone, reviews the electronic journal selections? 
Not reviewed $\square$

Dept. Head or Director $\square$

Systems Librarian $\square$

Electronic Resources Librarian $\square$

A special committee

Other (please specify)

10b) If you answered "special committee," what departments are the members from?

Acquisitions $\square$

Electronic Resources

Reference

Systems $\square$

Other (please specify)

11) Do you have a standardized procedure for negotiating license agreements of electronic journals, or is each journal treated as a separate case?

Standardized procedure ${ }^{\circ}$

Every journal is negotiated separately ${ }^{C}$

There is some standardization among e-journals with similar access criteria $\odot$ 12) Who negotiates license agreements for electronic journals in your library?

Acquisitions

Administrators $\square$

Cataloging

Collection Development $\square$

Consortium $\square$

Electronic Resources Librarian $\square$

Reference $\square$ 


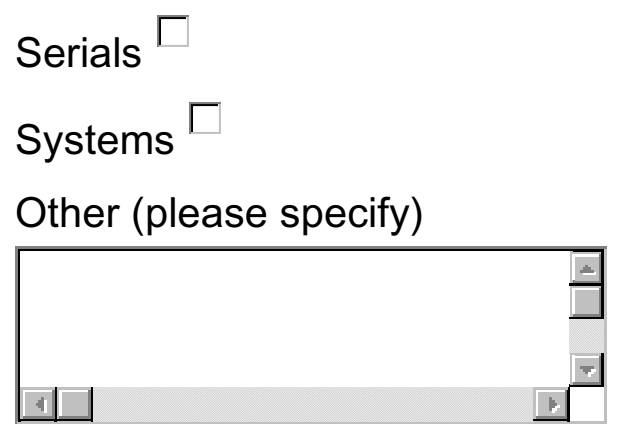

13) Do you have any special legal consultants who help with the licenses?

Yes ${ }^{\circ}$

No ${ }^{\circ}$

14) Because electronic journals are leased rather than owned, sometimes access to back issues is problematic. Which of the following groups currently archive back issues of your library's e-journals:

The library

Publishers

Vendors $\square$

Consortia $\square$

Not archived $\square$

Other (please specify)

15) How do you maintain bibliographic control over your electronic journals? Online catalog has direct links

Mount separate web page for electronic journals

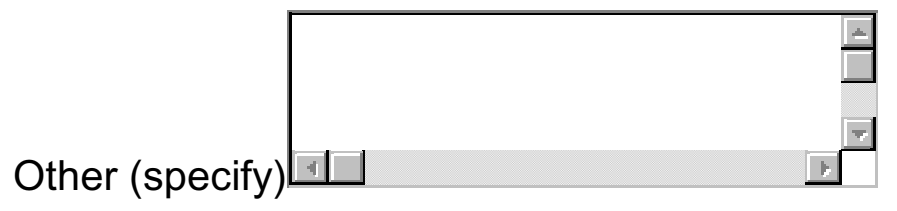

15b) What department is responsible for this?

Cataloging

Reference ${ }^{\circ}$ 
Serials ${ }^{\circ}$

Systems 0

Other (specify)

16) Maintenance of electronic journals is a continuous process due to the constant flux in journal holdings, frequency, access points, links, and content.

Who, if anyone, at your library updates electronic journals once they have arrived?

We rely primarily on link maintenance software ${ }^{\circ}$

We rely mostly on user feedback to become aware of changes 0

Catalogers ${ }^{\circ}$

Collection Development Librarians ${ }^{\circ}$

Electronic Resources Librarians ${ }^{\circ}$

Reference Librarians 0

Systems/Information Technology ${ }^{\circ}$

17) How many professional staff are employed by your library?

20-60

$61-100^{\circ}$

$101-140^{\circ}$

$141-180^{\circ}$

Over $180^{\circ}$

Do you have any additional comments about the survey?

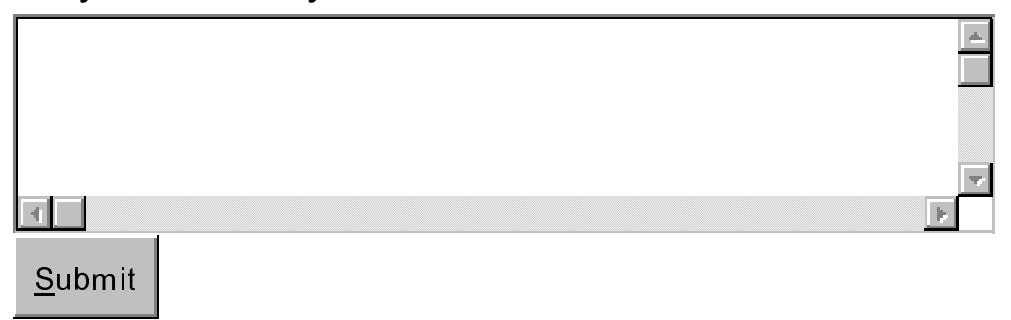




\section{Appendix C}

Distribution List

University of Alabama Libraries

University of Arizona

Arizona State University Libraries

Auburn University

Boston University

Boston Public Library

Brigham Young University

University of British Columbia

Brown University

University of California - Berkeley

University of California - Davis

University of California - Irvine

University of California - Los Angeles

University of California - Riverside

University of California - San Diego

University of California - Santa Barbara

Canada Institute for Scientific \& Technical Information (CISTI)

Case Western Reserve University

Center for Research Libraries

University of Chicago

University of Cincinnati Libraries

University of Colorado

Colorado State University

Columbia University

University of Connecticut

Cornell University 
Dartmouth College

University of Delaware

Duke University

University of Florida

Florida State University Library

Georgetown University

George Washington University

University of Georgia

Georgia Institute of Technology

University of Guelph

University of Hawaii

University of Houston

Howard University Libraries

University of Illinois - Chicago

University of Illinois - Urbana-Champaign

Indiana University

University of Iowa

Iowa State University

Iohns Hopkins University

University of Kansas

Kent State University Libraries

University of Kentucky

Louisiana State University

McGill University Libraries

McMaster University

University of Manitoba

University of Maryland

University of Massachusetts

Massachusetts Institute of Technology

University of Miami 
University of Michigan

Michigan State University

University of Minnesota

University of Missouri - Columbia

National Agricultural Library

National Library of Medicine

University of Nebraska - Lincoln

University of New Mexico

New York University

University of North Carolina - Chapel Hill

North Carolina State University

Northwestern University Library

University of Notre Dame

Ohio State University

Ohio University

University of Oklahoma

Oklahoma State University Library

University of Oregon

University of Pennsylvania

Pennsylvania State University Libraries

University of Pittsburgh

Princeton University

Purdue University

Queen's University

Rice University

University of Rochester

Rutgers University

University of Saskatchewan

Smithsonian Institution Libraries

University of South Carolina 
University of Southern California

Southern Illinois University

Stanford University

State University of New York - Albany

State University of New York - Buffalo

State University of New York - Stony Brook

Syracuse University

Temple University

University of Tennessee - Knoxville

University of Texas - Austin

Texas A\&M University Libraries

Texas Tech University Libraries

University of Toronto

Tulane University

University of Utah

University of Virginia

Virginia Tech

University of Washington

Washington State University

Washington University - St. Louis

University of Waterloo

Wayne State University

University of Western Ontario

University of Wisconsin - Madison

Yale University 


\section{Bibliography}

ARL (Association of Research Libraries). 7 June 2000. <http://www.arl.org>

Bjoernshauge, Lars. "Consortia Building and Electronic Licensing as Vehicles for ReEngineering Academic Library Services: The Case of the Technical Knowledge Center and Library of Denmark (DTV)." Issues in Science and Technology Librarianship Spring (1999): 8 pp. 15 May 2000 < http://www.library.ucsb.edu/istl/99-spring/article5.html >.

Bordeianu, Sever, Linda K. Lewis, and Frances C. Wilkinson. "Merging the Acquisitions and Serials Department At the University of New Mexico: A Case Study." Library Acquisitions: Practice \& Theory 22.3 (1998): 259-270.

Buckley, Chad, Marian Burright, Amy Prendergast, Richard Sapon-White, Anneliese Taylor. "Electronic Publishing of Scholarly Journals: A Bibliographic Essay of Current Issues." Issues in Science and Technology Librarianship Spring (1999): 12pp. 17 May $2000<$ http://www.library.ucsb.edu/istl/99-spring/article4.html>.

Chadwell, Faye A. and Sara Brownmiller. "Heads Up: Confronting the Selection and Access Issues of Electronic Journals." Acquisitions Librarian 21 (1999): 21-35.

Crump, Michael. "Acquiring and Managing Electronic Journals: Integrated Workload or Special Handling?" Technical Services Quarterly 16.1 (1998): 57-60.

Duranceau, Ellen Finnie. "Archiving and Perpetual Access for Web-Based Journals: A Look at the Issues and How Five E-Journal Providers Are Addressing Them." Serials Review 24.2 (1998): 110-114.

---. "Beyond Print: Revisioning Serials Acquisitions for the Digital Age." Serials Librarian 33.1 (1998): 83-106.

Dygert, Claire T. "New Challenges Behind the Scenes: The Changing Role of the Serials Librarian in the Age of E-Publishing." Internet Reference Services Quarterly 3.3 (1998): 7-14.

Ellis, Kathryn D. “Acquiring Electronic Journals.” Acquisitions Librarian 21 (1999): 519.

Gleason, Maureen L., and Lorenzo A. Zeugner Jr. "Ways of Change: An Acquisitions Department in the 1990's." Library Acquisitions: Practice \& Theory 22.3 (1998): 303309. 
Gomez, Joni. "Human Factors in the Electronic Technical Services." $\underline{\text { Acquisitions }}$ Librarian 21 (1999): 105-114. 
Hudson, Laura, and Laura Windsor. "Providing Access to Electronic Journals: The Ohio University Experience." Against the Grain 10.3 (1998): 1+.

Hunter, Karen. "Electronic Journal Publishing: Observations From Inside." D-Lib Magazine July/August (1998): 6pp. 16 May 2000

<http://www.dlib.org/dlib/july98/07hunter.html>

Johnson, Judy. "Handling E-Journals: A Report of the ALCTS Creative Ideas in Technical Services Discussion Group Meeting." Technical Services Quarterly (1998): 62-63.

Loghrya, Pat, Linda Hulbert, and Adolfo R. Tarango. "From Carnegie to Internet2: A Report From the 14th Annual Conference of the North American Serials Interest Group (NASIG). Library Collections, Acquisitions, and Technical Services 24.1 (2000): 127147.

Luther, Judy. "Whither Electronic Journals?" Against the Grain 12.2 (2000): 24+. McGinnis, Suzan, and Jan. H. Kemp. "The Electronic Resources Group: Using the Cross-Functional Team Approach to the Challenge of Acquiring Electronic Resources." Library Acquisitions: Practice \& Theory 22.3 (1998): 295-301.

Moothart, Tom. "Adding to User Confusion By Adding More E-Journals." Serials Review 24.3/4 (1998): 136-138.

Slight-Gibney, Nancy. "Periodical Acquisitions and the Internet: An Introduction." Acquisitions Librarian 21 (1999): 1-4.

Whithers, Rob. "Biz of Acq-- Selecting and Processing Electronic Resources: How to Plug Librarians Into the Workflow." Against the Grain 11.6 (2000): 80-83.

Van Wordragen, Eric Jan. "The Vendor's View of E-Journal Services" Serials Review 24.1 (1998): 102-104. 
